\title{
Single particle characterization using a light scattering module coupled to a time-of-flight aerosol mass spectrometer
}

\author{
E. S. Cross ${ }^{1}$, T. B. Onasch ${ }^{1,2}$, M. Canagaratna ${ }^{2}$, J. T. Jayne ${ }^{2}$, J. Kimmel ${ }^{2,3}$, X.-Y. Yu ${ }^{4}$, M. L. Alexander ${ }^{4}$, \\ D. R. Worsnop ${ }^{2}$, and P. Davidovits ${ }^{1}$ \\ ${ }^{1}$ Chemistry Department, Boston College, Chestnut Hill, Massachusetts, USA \\ ${ }^{2}$ Center for Aerosol and Cloud Chemistry, Aerodyne Research Inc., Billerica, Massachusetts, USA \\ ${ }^{3}$ CIRES, University of Colorado, Boulder, Colorado, USA \\ ${ }^{4}$ Pacific Northwest National Laboratory, Richland, Washington, USA
}

Received: 22 October 2008 - Published in Atmos. Chem. Phys. Discuss.: 23 December 2008

Revised: 13 July 2009 - Accepted: 26 September 2009 - Published: 19 October 2009

\begin{abstract}
We present the first single particle results obtained with an Aerodyne time-of-flight aerosol mass spectrometer coupled with a light scattering module (LS-ToF-AMS). The instrument was deployed at the T1 ground site approximately $40 \mathrm{~km}$ northeast of the Mexico City Metropolitan Area as part of the MILAGRO field study in March of 2006. The LS-ToF-AMS acquires both ensemble average and single particle data. Over a 75-h sampling period from 27 30 March 2006, 12853 single particle mass spectra were optically-triggered and saved. The single particles were classified based on observed vaporization histories and measured chemical compositions. The single particle data is shown to provide insights on internal AMS collection efficiencies and ambient mixing state information that augments the ensemble data.

Detection of correlated light scattering and chemical ion signals allowed for a detailed examination of the vaporization/ionization process for single particles measured with the AMS instrument. Three particle vaporization event types were identified as a fraction of the total number of particles detected: (1) $23 \%$ with prompt vaporization, (2) $26 \%$ with delayed vaporization, and (3) $51 \%$ characterized as null. Internal consistency checks show that average single particle nonrefractory mass and chemical composition measurements were in reasonable agreement with ensemble measurements and suggest that delayed and null vaporization events are the dominant source of the nonunit collection efficiency of the
\end{abstract}

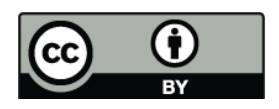

Correspondence to: E. S. Cross (crosse@bc.edu)
AMS. Taken together, the simultaneous prompt single particle and aerosol ensemble measurements offer insight into the mixing state and atmospheric transformations of ambient aerosol particles.

\section{Introduction}

To accurately model the radiative forcing of aerosol particles, one must measure in real-time the size, shape, density, chemical composition, and mixing state of ambient particles. This is a formidable challenge because the chemical and physical properties of the aerosol particles are highly complex, dependent on the emission sources, the geography and meteorology of the surroundings, and the gas phase composition of the regional atmosphere. As a result, aerosol particles continually change as they are transported through the atmosphere. Without a detailed understanding of the sources and atmospheric processes that control the chemical and physical transformations of the particles, the influence of aerosol particles on climate remains highly uncertain. Currently, uncertainties in the evaluation of aerosol direct and indirect radiative effects are the source of the largest uncertainty in estimating the overall radiative forcing of the climate (IPCC, 2007).

Urban areas produce large quantities of aerosol particles together with gas phase precursors that influence secondary aerosol formation. Emissions from the numerous sources within an urban environment cause adverse health effects, reduction in visibility, deposition of chemicals to the ecosystem, and direct and indirect radiative forcing that

Published by Copernicus Publications on behalf of the European Geosciences Union. 
are evident on local, regional, and global scales (Molina et al., 2007). The MILAGRO (Megacity Initiative: Local and Global Research Observations) field study was conducted in and around Mexico City during March of 2006 (http://www.eol.ucar.edu/projects/milagro/). The aim of the study was to obtain a more complete understanding of the atmospheric transformations that occur within the urban plume as it is transported away from the city. The part of the MILAGRO study described in this manuscript focused on the chemical transformations and source apportionment of the aerosol particles.

Until recently, available real-time quantitative instrumentation could provide only an average chemical composition for the ambient aerosol particle ensemble. To evaluate the radiative effects of the aerosol particles and to begin to identify their sources, average data are not necessarily sufficient. Consider for example two aerosol particles, one composed of purely carbonaceous material (organic carbon and elemental carbon or soot), and the other composed of purely inorganic material. The hygroscopicity, cloud condensation nuclei (CCN) activity, and optical properties of these two (externally mixed) aerosol particles may be significantly different than the hygroscopic, $\mathrm{CCN}$ and optical properties of two similarly-sized aerosol particles that are internally mixed (i.e. each particle composed of 50\% carbonaceous and 50\% inorganic material). Measuring the single particle chemical composition provides the information necessary to determine the ensemble mixing state and analyze the chemical transformations taking place as the particles undergo atmospheric processing. Some of the complexities of particle CCN properties due to coating and mixing are discussed in Petters et al. (2006), and Shilling et al. (2007). The effects on optical properties of particles due to coating, mixing, and aging processes are discussed in Chylek et al. (1995), Lesins et al. (2002), and Bond et al. (2006).

A key advance in atmospheric aerosol science has been the development of aerosol mass spectrometers that, with ongoing improvements and design modifications, can now measure size and chemical composition for individual particles within the ambient ensemble. For recent reviews on these instruments, see McMurry (2000), Sullivan and Prather (2005), Murphy (2007), Nash et al. (2006), and Canagaratna et al. (2007). One example of such an instrument, featured in this manuscript, is the aerosol mass spectrometer (AMS) developed by Aerodyne Research Inc. (Jayne et al., 2000).

The AMS instrument measures ensemble average chemical composition and size of submicron particles. Recently, the AMS has been redesigned to incorporate two new features that significantly expand the capability of the instrument to provide single particle information. First, the quadrupole mass spectrometer was replaced by a time-offlight mass spectrometer (TOFMS) (Drewnick et al., 2005; DeCarlo et al., 2006). With the TOFMS coupled to the AMS, single particle mass spectra can be obtained. (This combined instrument is known as a ToF-AMS.) The ToF-AMS can measure single particle nonrefractory chemical composition as a function of particle aerodynamic diameter. In 2005, Drewnick et al. demonstrated the ability of the ToF-AMS to acquire single particle mass spectra.

In the second modification, a light scattering module was integrated into the AMS instrument. This version of the instrument is referred to as the LS-AMS (Cross et al., 2007). The light scattering module provides a single particle measurement of scattered light intensity $\left(R_{\mathrm{LS}}\right)$ for particles above $d_{\mathrm{p}} \sim 250 \mathrm{~nm}$ that enter the AMS and impact on the heated vaporizer. A single calibration curve converts $R_{\mathrm{LS}}$ to an optical diameter $\left(d_{\mathrm{o}}\right)$. Using the relationship between $d_{\mathrm{o}}$ and the simultaneously measured vacuum aerodynamic diameter $\left(d_{\mathrm{va}}\right)$ (Cross et al., 2007), the LS-AMS provides real-time, per particle measurements of the density and total mass of the sampled aerosol particles (Slowik et al., 2004; DeCarlo et al., 2004). Further, the LS-AMS provides a number-based measure of the internal collection efficiency of the AMS by comparing the number of chemically detected particles to the total number of optically detected particles.

The light scattering module has now been added to the ToF-AMS. In this new instrument combination, the acquisition of mass spectra for each particle is triggered by a light pulse scattered by the particle. This instrument is designated as the LS-ToF-AMS. The LS-ToF-AMS uses thermal desorption and continuous electron impact ionization of single particles, enabling the detection and classification of ambient single particles based on their nonrefractory chemical compositions. This new approach is unique among current field deployable single particle mass spectrometers.

The optical triggering improves the effectiveness and efficiency of the AMS as a single particle mass spectrometer by minimizing the number of data files saved and postprocessing steps required to identify individual particles. The presence of the light scattering module does not influence the instrument's ability to measure the ensemble average chemical composition and size distribution. Therefore, the LSToF-AMS can measure both ensemble average and single particle properties (e.g. mixing state) of the ambient aerosol by alternating data acquisition modes.

In this article, we present results obtained with the LS-ToF-AMS during the MILAGRO field study in Mexico City in March 2006. The LS-ToF-AMS was located at the T1 sampling site $\sim 40 \mathrm{~km} \mathrm{NE}$ of the city center. (See the MILAGRO/INTEX-B 2006 special issue of Atmospheric Chemistry and Physics for other results from the MILAGRO field experiment). Typical AMS measurements of submicron, nonrefractory aerosol chemistry and chemically-speciated size distributions were obtained from 12-30 March 2006 with several interruptions due to power failures and instrument calibrations. The LS-ToF-AMS successfully characterized the size, chemical composition, and mixing state of individual particles over a 75-h period from 04:27 LT on 27 March to 07:24 LT on 30 March 2006. The ensemble average size and chemical composition were also 


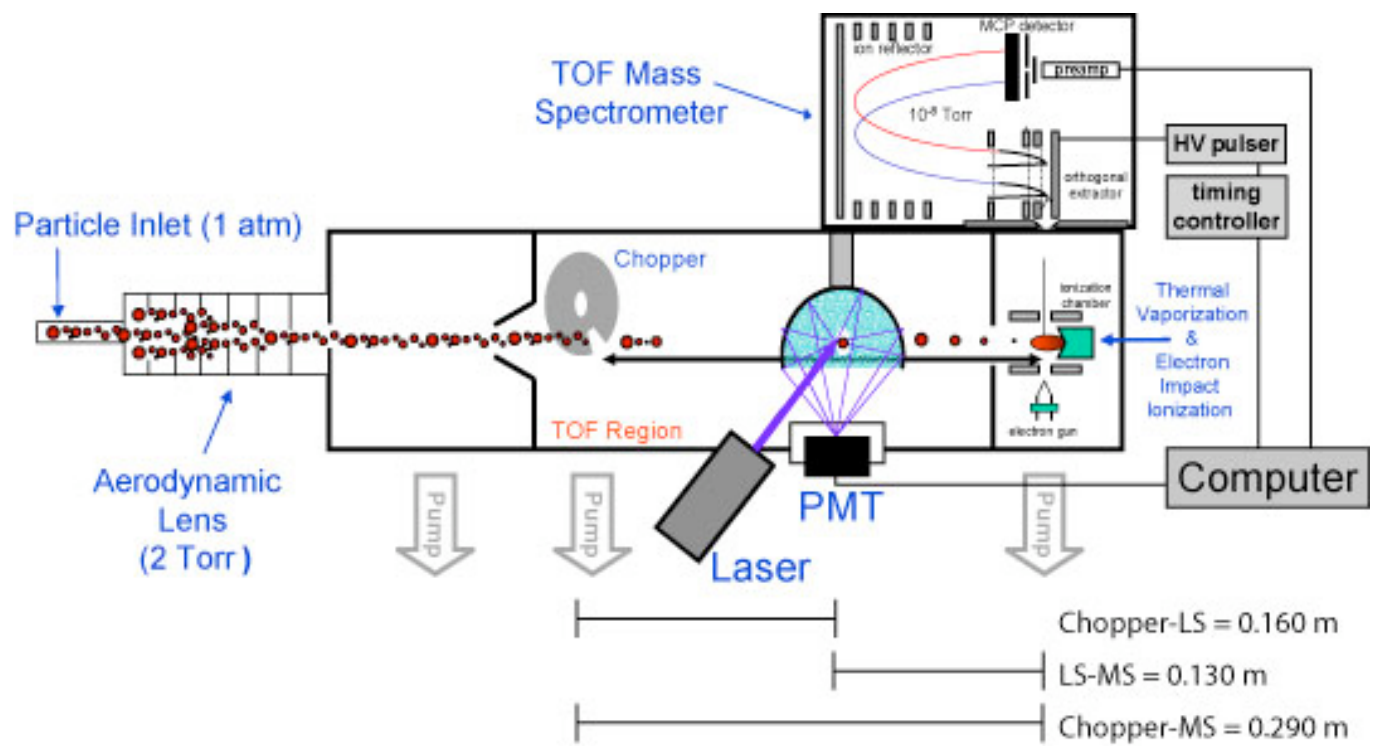

Fig. 1. Schematic of the LS-ToF-AMS.

obtained for this period using the same AMS instrument. This manuscript highlights the results of the single particle measurements made with the new LS-ToF-AMS instrument combination.

\section{Experimental methods}

\subsection{Instrumentation}

\subsubsection{LS-ToF-AMS}

A schematic of the LS-ToF-AMS equipped with the light scattering module is shown in Fig. 1. Individual components of the instrument have been described in other publications (Cross et al., 2007; Jayne et al., 2000; Jiménez et al., 2003; DeCarlo et al., 2006; Drewnick et al., 2005). Here we provide a brief overview of the instrument. The LS-ToF-AMS consists of three main sections: (1) aerodynamic lens, (2) particle time-of-flight region, and (3) particle vaporizer together with the TOFMS. As shown in Fig. 1, the light scattering module is located in the particle time-of-flight region between the aerodynamic lens and the vaporizer surface.

In the LS-ToF-AMS, particles were sampled from ambient pressure (590 Torr at T1 in Mexico City) into an aerodynamic lens through a critical orifice. The aerodynamic lens used during MILAGRO 2006 was a "high throughput" lens style (as opposed to the standard AMS lens style) and was operated with a $130 \mu \mathrm{m}$ critical orifice (compared with the typical $100 \mu \mathrm{m}$ critical orifice size) (Liu et al., 2007). In their passage through the lens, particles were accelerated by the pressure drop, $\sim 2$ Torr inside the lens and $<10^{-4}$ Torr in the time-of-flight region. The aerodynamic lens focused particles towards a rotating mechanical chopper, which modulated the particle beam. The chopper was mounted at the front of the particle time-of-flight chamber. The alignment of the $1 \%$ chopper slit opening with the particle beam defined $t_{0}$ for the particle time-of-flight. At the end of the time-of-flight region, particles impacted a heated surface $\left(\sim 600^{\circ} \mathrm{C}\right)$ and the nonrefractory species were flash vaporized. In the LS-ToFAMS, like the standard AMS, refractory material (e.g. elemental carbon, metals, and minerals) is not effectively vaporized. The resulting plume of vapor was ionized by electron impact $(70 \mathrm{eV})$ and the ions were transferred to the TOFMS. Mass spectra were acquired and stored in a manner that depended on the mode of operation of the AMS as described in Appendix A.

The light scattering module consists of a diodepumped $405 \mathrm{~nm}$ continuous wave $50 \mathrm{~mW}$ laser (CrystaLaser, LC BCL-050-405), external mirrors for alignment of the light beam, an ellipsoidal mirror for scattered light collection (Opti-Forms E103-2-01), a razor blade beam stop for quenching the throughput laser light, and a photomultiplier tube (PMT) for scattered light detection (Hamamatsu H6779-00). An optical scattering signal $\left(R_{\mathrm{LS}}\right)$ is obtained for nearly every particle that impacts the surface of the vaporizer (3.8 $\mathrm{mm}$ in diameter) if the particle is larger than the optical size detection limit, in this case $d_{\mathrm{p}} \sim 250 \mathrm{~nm}$. As detailed in Cross et al. (2007), this purposeful defocusing of the light scattering laser beam allows for the near complete optical detection of spherical and non-spherical particles sampled by the LS-ToF-AMS before the particles impact the vaporizer. 


\subsection{Data acquisition}

Three different data acquisition modes were utilized during the 75-h period of single particle sampling: the standard ensemble average modes of the AMS - Mass Spectrum (MS) mode and Particle Time-of-Flight (PTOF) mode and the new Light Scattering Single Particle (LSSP) mode where optically-triggered single particle mass spectra were saved. The measurements presented in this paper were saved in $5 \mathrm{~min}$ intervals. At the conclusion of each saving interval, one PTOF file, one MS file, and one LSSP file was saved. During the first $150 \mathrm{~s}$ of the saving interval, the instrument was alternated every $10 \mathrm{~s}$ between MS and PTOF modes. During the second $150 \mathrm{~s}$, the instrument was operated in LSSP mode. During each LSSP saving interval, 15 to 30 single particles were sampled (data transferred and saved) depending on the ambient particle concentration. By comparison, in the PTOF mode, chemical signals from $\sim 2000$ particles were averaged during each $75 \mathrm{~s}$ PTOF sampling period and $\sim 50000$ particles were averaged in MS mode. The three data acquisition modes are described in detail in Appendix A.

\subsection{Sampling site and meteorology}

The T1 sampling site was located at Tecamac University (19.703 N Latitude and 98.982 W Longitude) at an elevation of $2273 \mathrm{~m}, \sim 40 \mathrm{~km} \mathrm{NE}$ of the Mexico City metropolitan area (MCMA). T0 was the site within city center and T2 was located $35 \mathrm{~km} \mathrm{~N}-\mathrm{NE}$ of T1. The location of these three field sites was chosen such that each would intercept the MCMA plume as it is transported away from the city center to the North (Doran et al., 2008). The area surrounding T1 consists of built up, highly populated residential neighborhoods and less developed regions with open fields. The residential regions are to the south and east of T1. The less developed areas are toward the north and west. A major commuting highway between Mexico City and Pachuca is $\sim 1 \mathrm{~km}$ to the east of the site. The LS-ToF-AMS operated in combined single particle and ensemble aerosol modes from 27 to 30 March 2006. The meteorology in the Mexico City basin during these three days was influenced by a "cold-surge" or "Norte" event on 23 March 2006 that brought higher humidity and westerly winds to the Mexico City basin. The mornings at $\mathrm{T} 1$ were clear, the afternoons partly cloudy with isolated convection and precipitation events, and the ground level winds favorable for transport from the city center to T1, while biomass burning was lower during this period than during the first 20 days of the MILAGRO campaign (Fast et al., 2007; de Foy et al., 2008).

\section{Single particle analysis}

In our current study, 12853 single particle mass spectra were recorded and analyzed during a 75-h sampling period. The following information was obtained for each individual particle: vacuum aerodynamic diameter $\left(d_{\mathrm{va}}\right)$, optical diameter $\left(d_{\mathrm{o}}\right)$, and a mass spectrum. Using this information, multiple internal consistency checks were performed on the single particle data to ensure data acquisition and processing quality. For example, we examine the timing and efficiency of the vaporization/ionization process for each optically-detected particle: single particles exhibit prompt, delayed, or null vaporization. The correlated single particle measurements of $d_{\mathrm{va}}, d_{\mathrm{o}}$, and chemical ion signals provides for a comparison between two independent measures of single particle mass (i.e. nonrefractory and total). Finally, knowing the sampling duty cycles for the LSSP, PTOF, and MS modes allows for a direct comparison between the average single particle and ensemble results.

The chemical compositions of single particles were analyzed using standard AMS analysis techniques and the prompt single particles were classified into different particle types based on nonrefractory chemical mass fractions. These prompt single particle types are the basis for the study of ambient aerosol mixing states described in Sect. 4. The observation of particle coincidence in the system provides a simple demonstration of the capability of the LS-ToF-AMS to determine the mixing state of sampled aerosol.

\subsection{Single particle vaporization events}

The light scattering module counts, sizes, and correlates the light scattering signal with the TOF-MS chemical ion signals for particles with diameters greater than $d_{\mathrm{p}} \sim 250 \mathrm{~nm}$. By collecting the scattered light from sampled particles $(>250 \mathrm{~nm})$, the vaporization/ionization process in the LS-ToF-AMS can be examined on a single particle basis. During the 75-h of single particle sampling, $\sim 49 \%$ of all optically detected particles produced a measurable chemical ion signal while the remaining $\sim 51 \%$ did not produce a clearly detectable chemical signal.

The optically detected particles can be classified based on their measured vaporization times. The time-of-flight between the chopper opening and the optical scattering signal provides a measure of the particle velocity, independent of chemical detection. The arrival time of each particle at the vaporizer surface is calculated and compared with the observed time of the chemical ion pulse. Based on the timing of the observed chemical ion signal, single particle vaporization events are classified as either: prompt, delayed, or null.

Prompt particles are those that produced a chemical ion signal within $200 \mu$ s of impacting the vaporizer surface. The timing of each single particle chemical ion signal measured with the LS-ToF-AMS contains two elements of timing uncertainty. (1) the uncertainty in the $t_{0}$ due to the slit width of the spinning chopper wheel $(1 \%$ at $130 \mathrm{~Hz})$ and (2) the additional time it takes a particle to vaporize, be ionized, and detected (called vaporization/ion flight time). The range of vaporization/ion flight times for $\mathrm{NH}_{4} \mathrm{NO}_{3}(80 \mu \mathrm{s}),\left(\mathrm{NH}_{4}\right)_{2} \mathrm{SO}_{4}$ 
$(150 \mu \mathrm{s})$ and PSL $(200 \mu \mathrm{s})$ particles serves as a rough guide for the range of vaporization/ion flight times expected for the ambient ensemble. Although not perfect, the $200 \mu$ s upper limit for prompt particle classification ensures that particles that vaporize upon initial impact with the vaporizer surface are counted as prompt. Delayed particles produce a chemical ion signal $>200 \mu$ s after the calculated arrival time at the vaporizer. Null particles do not produce a clear single particle chemical ion signal within the remaining PTOF time window $(\sim 2.5 \mathrm{~ms})$. In the MILAGRO study, the number fractions of the prompt, delayed, and null particles were $0.23,0.26$, and 0.51 , respectively.

The observation of prompt, delayed, and null particle vaporization events with the LS-ToF-AMS provides direct evidence that particle bounce is occurring within AMS instruments. The phenomenon of particle bounce upon impact with vaporizer surfaces has been reported previously in the literature (e.g. Sinha and Friedlander, 1985; Matthew et al., 2008). These measurements confirm that bounce is occurring during ambient sampling and offers insight into the extent to which particle bounce plays a role in the vaporization/ionization processes in the AMS. Prompt vaporization events reflect particles that vaporize immediately upon impact with the vaporizer. The time lag of the delayed particles, on the other hand, reflects the fact that these particles do not vaporize immediately upon impact but most likely bounce and then vaporize upon secondary impacts with the vaporizer edges or hot ionizer cage surfaces. As discussed in detail in Sect. 3.2 and 3.3, the delayed/null single particle vaporization event types represent particle bounce events that lead to undetected nonrefractory particulate mass. For example, the absence of chemical ion signal in the LS-ToF-AMS in the null particle vaporization events arises from bounce related events which physically cause particles to be ejected out of the heated ionization region without vaporizing measureable ion signal within the PTOF time window. It also important to note that some of the missing mass from these single particle vaporization event types (i.e. prompt, delayed, or null) could be due to refractory material present in the particles (i.e. black carbon, metals, and minerals that do not readily vaporize at the $600^{\circ} \mathrm{C}$ vaporizer temperature of the $\mathrm{AMS}$ ).

The number fractions of the single particle vaporization events exhibited slight temporal and size dependencies. Figure 2a shows a time trend of the number fraction of prompt, delayed, and null particles. These time trends exhibit a minor diurnal variation; however, the variation is within $\pm 10 \%$ over the full sampling period indicating that there was little variation in the number-based collection efficiency during this study. Figure $2 \mathrm{~b}$ shows a histogram of the total number of single particles optically detected during the $75 \mathrm{~h}$ sampling period as a function of the particle time of flight (PTOF time - i.e. time elapsed from the chopper opening) and vacuum aerodynamic diameter $\left(d_{\mathrm{va}}\right)$. The total number of sampled single particles peaks between $1.45-1.75 \mathrm{~ms}(230-420 \mathrm{~nm}$ $\left.d_{\mathrm{va}}\right)$. The decrease in detected single particles to smaller
PTOF times ( $d_{\mathrm{va}}$ sizes) is largely due to the detection limit of the light scattering module. The decrease to the larger PTOF times $\left(d_{\mathrm{va}}\right.$ sizes) is due to the convolution of the ambient particle size distributions and the size-dependent AMS aerodynamic lens transmission function (Jayne et al., 2000; Liu et al., 2007). The single particle vaporization event types (prompt, delayed, and null) are also shown as a fraction of the total particles detected as a function of PTOF time $\left(d_{\mathrm{va}}\right.$ size), for all bins containing 90 or more detected particles.

The single particle vaporization event types show a slight size dependence. The fraction of prompt particles detected decreases with increasing particle size $\left(d_{\mathrm{va}}\right)$, while the fraction of delayed and null particle types increase with increasing particle size. The increase in null and delayed detection of larger single particles within the LS-ToF-AMS could be due to either the reported increase in the fraction of refractory particles present in the ambient atmosphere (e.g. increase in dust particle number fraction with size; Querol et al., 2008; Aiken et al., 2009) or more bounce events with less than total vaporization of the non-refractory components due to the greater momentum of the larger particles. It is also possible that delayed particles at the smallest detectable sizes cannot be detected as efficiently as prompt particles, as the former ones may not exceed the ion count thresholds at any given PTOF bin that separate particle detection from non-detection. The additional information provided by the optically detected single particles will facilitate future studies of particle collection efficiencies within AMS instruments.

\subsection{Estimation of single particle mass for prompt and delayed events}

Each single particle mass spectrum represents the ions collected from the nonrefractory component of a given particle that vaporized on the heated vaporizer and was subsequently ionized via electron impact, extracted, and detected by the TOF-MS. As the correlated light scattering and chemical ion signals have allowed for the classification of different particle vaporization event types (i.e. prompt, delayed, and null), it is apparent that not all of the single particle nonrefractory mass may be detected for any given particle. One method for addressing the ambiguity in collection efficiencies (i.e. missed particulate material could be either refractory, which cannot be detected in an AMS, or nonrefractory, which is lost due to particle bounce prior to full vaporization, or both) is to compare the chemical ion signals (i.e. nonrefractory particle mass) to an independent method for measuring single particle mass (nonrefractory + refractory). The method for estimating total single particle mass $\left(m_{\mathrm{p}}\right)$ combines $d_{\mathrm{o}}$ and $d_{\mathrm{va}}$ measurements: $m_{\mathrm{p}}=\pi / 6 \times d_{\mathrm{o}}^{2} \times d_{\mathrm{va}}$ (Cross et al., 2007). The direct comparison of these two independent measurements provides an insitu method for estimating the amount of the total single particle mass detected chemically, albeit with the uncertainties associated with $d_{0}$ measurements (i.e. shape and refractive index). 

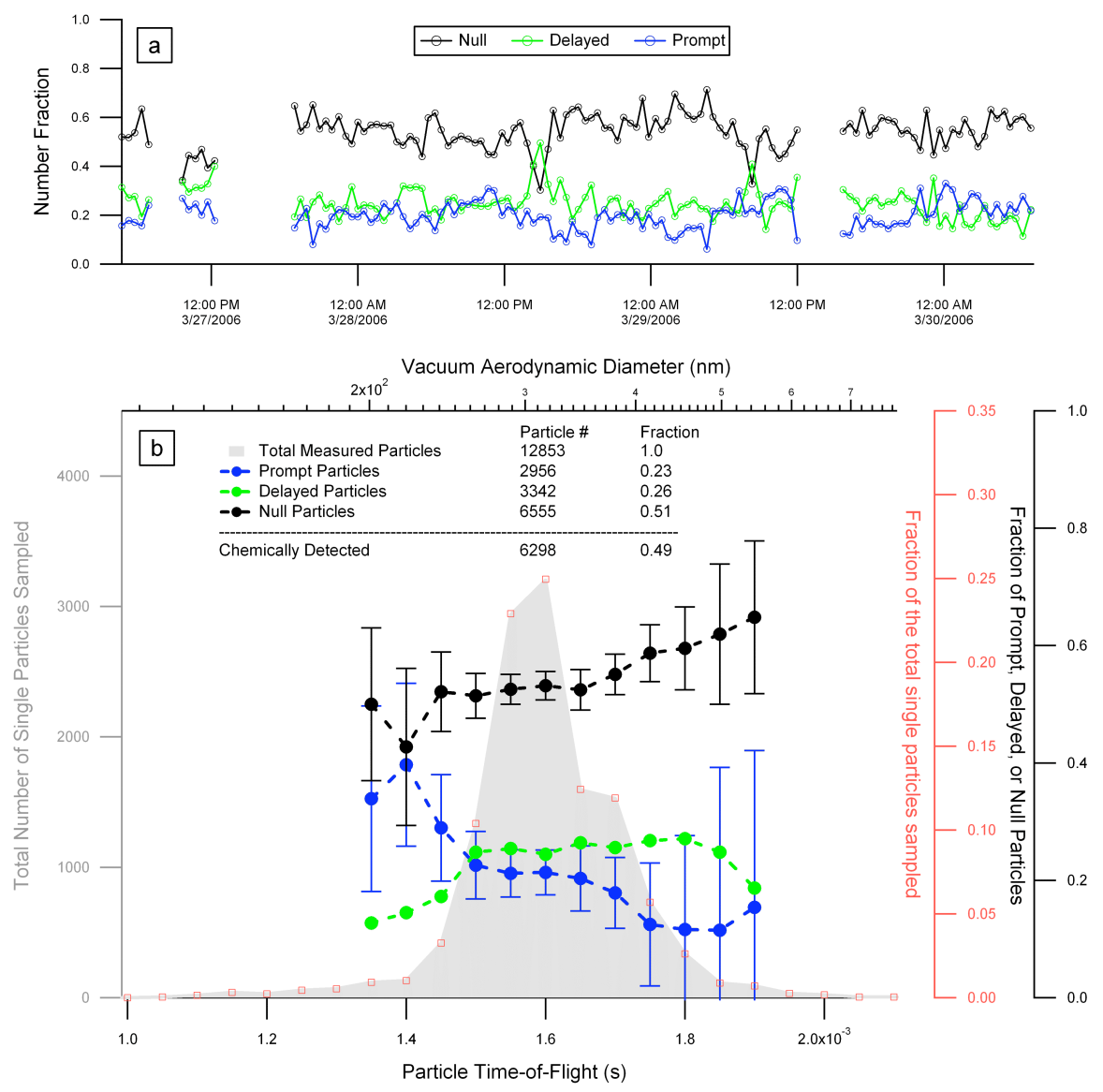

Fig. 2. Total particle counts (in grey) and number fractions of prompt (blue), delayed (green) and null (black) particles as a function of time-of-flight between the chopper and the light scattering module (bottom axis) and vacuum aerodynamic diameter (top-axis).

Figure $3 \mathrm{a}$ and $\mathrm{b}$ show the measured nonrefractory single particle mass obtained via calibration from the sum of all ion signals measured with the mass spectrometer for prompt and delayed particles, respectively. In each plot, the mass obtained from the chemical measurement is plotted against the single particle mass derived from the measured $d_{\mathrm{va}}$ and $d_{\mathrm{o}}$. The $d_{\mathrm{va}}$ measurements in Fig. 3 are derived from the time-of-flight between the chopper and the light scattering module. The HOA mass fraction of each particle is shown by the color of the data points in each figure.

The data displayed in Fig. 3a and b show considerable scatter due to uncertainties in both single particle measurements (i.e. chemical ion signal intensity and diameter measurements used to calculate total particle mass). Still, certain features are clearly evident. As is shown in Fig. 3a for the prompt vaporization events, the two independent measures of single particle mass are clustered near the 1:1 line. A linear fit of the data yields slope of 0.81 (intercept $<2$ femtograms; $R^{2}=0.5$ ). The data in Fig. 3a exhibit a significant scatter that is correlated with the HOA mass fraction in the particle. The ensemble HOA mass fraction (discussed further in Sect. 4.1.2) is correlated in time with particulate elemental carbon and gas phase $\mathrm{CO}$ measurements. These correlations, together with other published observations (Slowik et al., 2004; Canagaratna et al., 2004; Zhang et al., 2005b, c), suggest that HOA is often present in particles that contain fractal-like elemental carbon cores. This nonspherical, refractory material does not produce a chemical ion signal in the AMS and reduces the reliability of the $d_{\mathrm{o}}$ measurement due to shape and light absorption effects. Removing the particles with high fractional HOA content $(>10 \%)$, increases the slope (0.88) and $R^{2}(0.57)$ of the linear fit.

The data obtained from the delayed vaporization events are shown in Fig. 3b. This set of data exhibits significantly larger scatter and lower overall chemical ion signals than obtained from the prompt vaporization events. A linear fit to the data in Fig. $3 \mathrm{~b}$ has a slope of $0.41\left(R^{2}=0.12\right)$, indicating no clear correlation between the two measurements and suggesting that the measured chemical ion signals from delayed particle vaporization events generates a significantly lower percentage of the total single particle mass than that of prompt events. Thus, delayed vaporization events may indicate that the measured single particles either had a significant refractory component that was not detected or the particles 


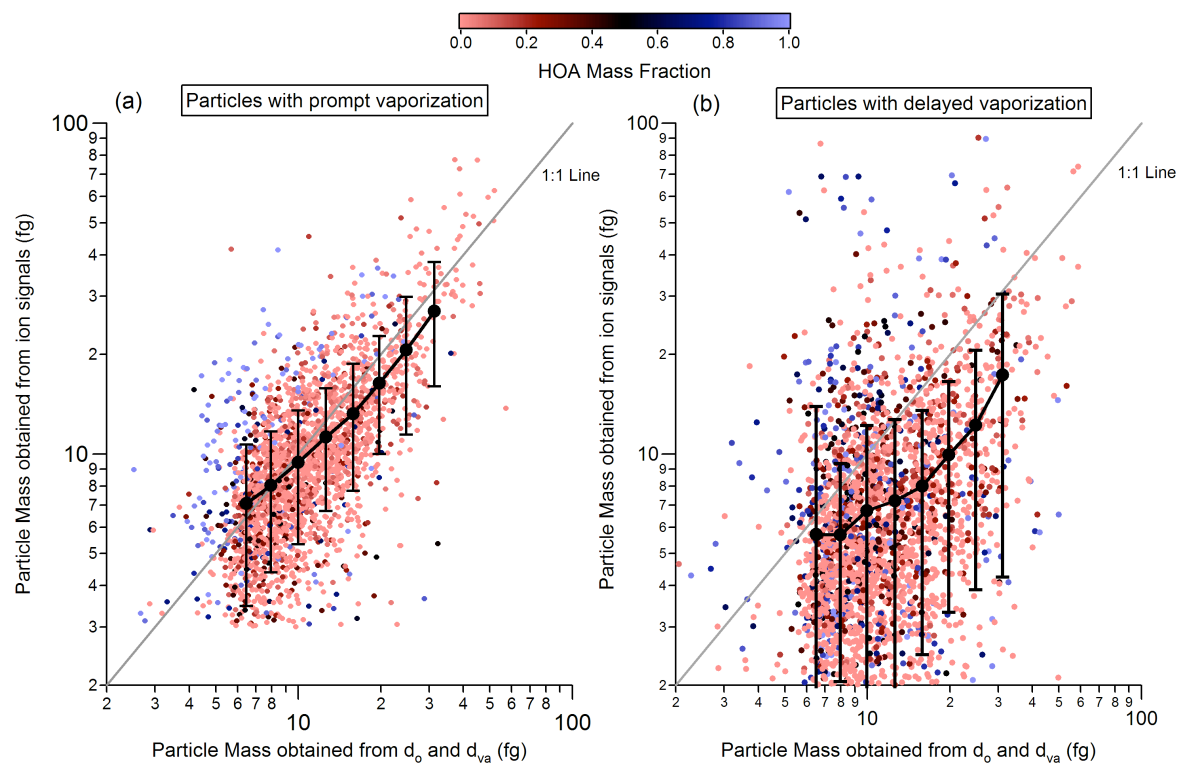

Fig. 3. Measured single particle mass obtained from chemical ion signals plotted versus single particle mass obtained from optical diameter $\left(d_{\mathrm{O}}\right)$ and vacuum aerodynamic diameter $\left(d_{\mathrm{va}}\right)$ measurements for (a) particles with prompt vaporization and (b) particles with delayed vaporization.

bounced prior to full vaporization of the nonrefractory components. As discussed in Sect. 3.3, delayed and null particle vaporization events likely generate more particulate ion signals during the longer time frames of the MS mode compared with LSSP and PTOF modes.

Although the single particle mass measurements displayed in Fig. 3a and $b$ exhibit significant scatter, the data still offer a valuable comparison between the prompt and delayed particle events. Namely, single particle chemical ion signals from promptly vaporized particles are reasonably correlated with the calculated single particle mass while delayed particles result in partial detection of the single particle mass derived from the diameter measurements. The uncertainties that contribute to the chemical ion signal measurement and calculation of single particle mass from the two diameter measurements are discussed in Appendix B.

\subsection{Single particle and ensemble data comparisons}

The LS-ToF-AMS was operatated in LSSP, PTOF, and MS modes. Internal comparisons between the different modes of data collection provides a consistency check for the new LSSP mode and provides insights into the collection efficiency of the AMS.

The LSSP and PTOF modes should provide the same particle information once the differences in measurement duty cycle and particle size detection limits (i.e. LSSP mode is limited to particle sizes $>250 \mathrm{~nm}$ ) have been taken into account. We plot the total chemical ion signals from single particles (LSSP) averaged over the $75 \mathrm{~h}$ sampling period and the simultaneous ensemble average (PToF) ion signals in
Fig. 4a. In each case, the data have been scaled according to the sampling duty cycle of each acquisition mode. The ensemble data is shown as a dashed line and the single particle data is shown in red. The summed chemical ion signals from the single particles are also shown for the observed vaporization event types: prompt (blue), delayed (green), and null (black). The detection limit of the LSSP mode for small particles is evident in Fig. 4a. In the MILAGRO study, the LSSP mode detected most particles with diameters larger than $d_{\mathrm{p}} \sim 250 \mathrm{~nm}\left(d_{\mathrm{va}} \sim 350 \mathrm{~nm}\right.$ or PToF $3.1 \times 10^{-3} \mathrm{~s}$ ), whereas the PTOF mode measured particles down to $d_{\mathrm{va}} \sim 30 \mathrm{~nm}$ (with arrival times at the vaporizer $\sim 1.5 \times 10^{-3} \mathrm{~s}$ or greater). The absolute lower size limit is determined by the convolution of ambient particle size distributions and the transmission cut-off for the aerodynamic lens inlet (Liu et al., 2007). About half of the particle mass detected in PTOF mode was present in particles too small for LS detection.

For particles larger than $d_{\mathrm{va}} \sim 350 \mathrm{~nm}(3.1 \mathrm{~ms}$ PTOF) the total summed ion signal measured in the LSSP mode is in reasonable agreement with the signal measured in the PTOF mode over the same size range. The correlation between the LSSP and PTOF signals for particle arrival times between 3.1-5.5 ms (data between arrows in Fig. 4a) is shown in Fig. 4b. The correlation is linear $\left(R^{2}=0.99\right)$ with a slope of 0.85 , indicating that the total averaged single particle ion signal is measuring $85 \%$ of the ensemble average PTOF mass across the optically detected size range. One possible reason for this difference could be delayed vaporization of particles smaller than the optical size detection limit which are not detected in the LSSP mode. This interpretation is supported by 


\begin{tabular}{|lcc|}
\hline Total LS-SP & Number Fraction & Mass Fraction \\
- & & \\
Prompt Particles & 0.23 & 0.59 \\
- Delayed Particles & 0.26 & 0.38 \\
- Null Particles & 0.51 & 0.03 \\
\hline- - Bulk Ensemble Data & & \\
\hline
\end{tabular}
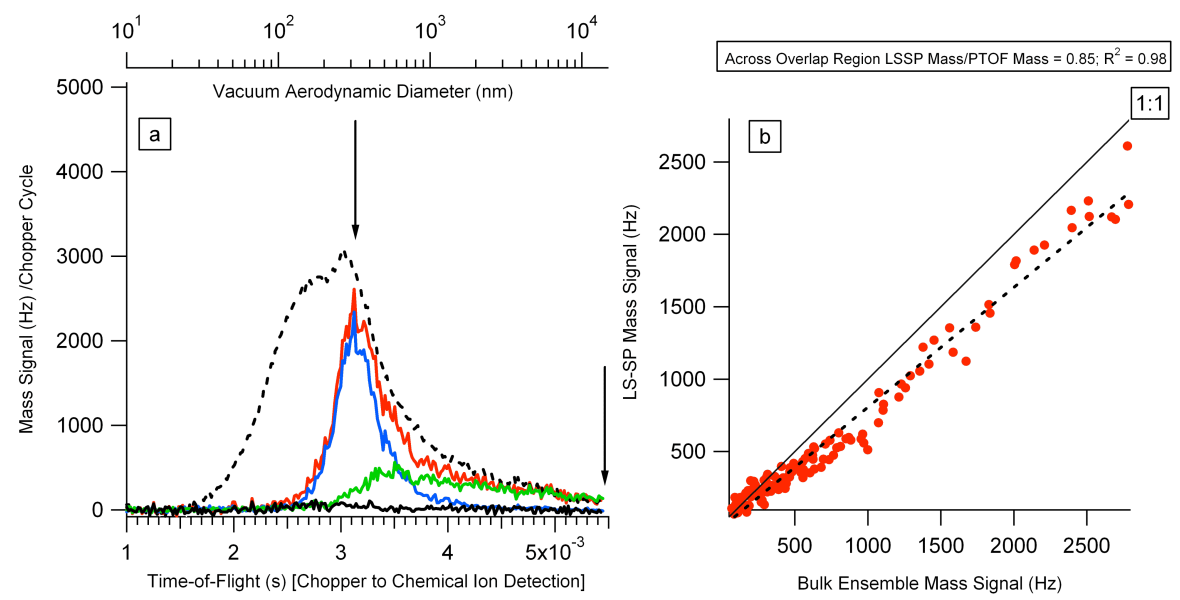

Fig. 4. (a) Average mass distributions as a function of particle time-of-flight for ensemble data (dashed black line) and total single particle data (red line). Distributions for prompt (blue), delayed (green) and null (black) particles are also shown. (b) Correlation plot between the average PTOF and total single particle mass measurements for times-of-flight between 3.1-5.5 ms, denoted with arrows in (a).

the fact that at longer PTOF ( $>4.8 \mathrm{~ms}$ in Fig. $4 \mathrm{a}$ ), the LSSP and PTOF mass signals agree fully.

In addition to the total ion signals, the chemical compositions of the aerosol as measured by the LSSP and PTOF modes agree well. The speciated mass fractions measured by the average LSSP mode $\left(\mathrm{NH}_{4}\right.$ concentration calculated assuming complete neutralization of the inorganic components $\mathrm{SO}_{4}, \mathrm{NO}_{3}$, and $\mathrm{Chl}$ for reasons discussed in Sect. 3.4) and the averaged, integrated PTOF mode (only including the size range relevant to the LSSP mode, $d_{\mathrm{va}} \geq 350 \mathrm{~nm}$ ) agree to within $\sim 25 \%$ during the full sampling period.

The comparison between the LSSP and PTOF mode data offers three observations. First, if LSSP and PTOF modes had similar particle size detection limits, it is likely that these two modes provide the same ensemble averaged mass loading and chemical composition information (accounting for the different duty cycles). The second observation is that the sampled ambient ensemble PTOF mode data (for the LSToF-AMS during MILAGRO) is broadened to larger particle sizes $\left(d_{\mathrm{va}}\right)$ due to delayed single particle vaporization events. While this data set is not definitive, the comparison between the PTOF distribution and the LSSP prompt particle distribution appears to indicate that the PTOF mass distribution mode is reasonably well represented (position and FWHM) and the delayed particle distribution creates a tailing to larger particle sizes that only significantly affects the large particle tail of the size distribution. The third observation is that the tailing of chemical ion signal continues to longer PTOF times than shown in Fig. 4 a (defined by chopper spinning frequency) implying that at longer times, more particle mass may evolve and be detected.

One key difference between the PTOF and LSSP modes (ensemble and single particle operation, respectively) and the MS mode is sampling time. In the MS mode, the sampling interval during which all chemical ion signals are averaged is typically on the order of several seconds ( $5 \mathrm{~s}$ during MILAGRO) compared to several milliseconds (5.4 ms during MILAGRO) for the LSSP and PTOF modes. As shown in Fig. $4 \mathrm{a}$, this difference in sampling timescales is important because particle bounce can cause vaporization timescales to be delayed enough that the particles do not completely vaporize on the sampling timescale of the LSSP and PTOF modes. Comparisons of chemically-speciated aerosol mass loadings (not including $\mathrm{NH}_{4}$ ) from integrated PTOF distributions with average MS data during this campaign indicates an average ratio of PTOF/MS of $\sim 75 \pm 20 \%$ (variation due to slight temporal cycle), suggesting that delayed/null particle events evolve more of their signal on the longer MS sampling scale. Despite this difference, the mass fractions of organic and inorganic species derived from the integrated PTOF and the average MS mass spectra agree within $\sim 20 \%$ (not including $\mathrm{NH}_{4}$ ). Thus, particle bounce impacts the total magnitude of ion signals measured in averaged-LSSP, PTOF and MS modes (LSSP $\sim \mathrm{PTOF}<\mathrm{MS}$ ), but not the chemical speciation of the sampled aerosol. Due the observed differences between the PTOF and MS modes, PTOF mode data is routinely normalized to the MS mode species concentrations in the AMS data analysis software. 
As the MS mode represents the most complete collection of available chemical ions, ambient mass concentrations are derived from MS mode and subsequently scaled by an empirical collection efficiency (CE) factor (Jimenez et al., 2003; Alfarra et al., 2004; Quinn et al., 2006; Matthew et al., 2008). For ambient AMS measurements, the CEs range between 0.45 and 1 (e.g. Canagaratna et al., 2007, and references therein). The nonrefractory mass-based collection efficiency of the LS-ToF-AMS during MILAGRO was determined to be $\sim 0.5$ by comparisons with co-located SMPS-derived apparent mass distributions and black carbon measurements, and with direct comparison with a C-ToF-AMS deployed in the Aerodyne mobile laboratory during a two day visit to the $\mathrm{T} 1$ site (Herndon et al., 2008). A mass-based CE of 0.5 has also been determined and verified independently by several other groups that have deployed AMSs to Mexico City during MCMA-2003 and MILAGRO, including Salcedo et al. (2006), Johnson et al. (2008), Kleinman et al. (2008), DeCarlo et al. (2008), Paredes-Miranda et al. (2009), and Aiken et al. (2009).

The LS-ToF-AMS data presented in this paper provides direct evidence that the mass-based collection efficiency of the AMS is a result of particle bounce. The nonrefractory mass for prompt single particle vaporization events is collected with near unit efficiency while delayed and null particle events contain mass that is undetected on the PTOF timescale. The AMS mass-based $\mathrm{CE}=0.5$ for this campaign indicates that $50 \%$ of the nonrefractory particulate material sampled is not detected, even in the longer MS mode timescales. Since refractory species account for only $20 \%$ of the submicron ambient PM in Mexico (Querol et al., 2008; Aiken et al., 2009; Salcedo et al., 2006; Chow et al., 2002), these observations strongly suggest that the non-unit massbased CE in this campaign is a result of delayed/null single particle vaporization events during which nonrefractory material was not completely detected.

Evidence that the nonrefractory particulate measurements of the AMS and, thus, the LS-ToF-AMS single particle measurements, represent the nonrefractory ambient aerosol chemistry and mass loadings come from detailed studies comparing the AMS measurements, corrected with appropriate mass-based CEs, with independent instruments. Previous publications have shown AMS measurements to reproduce both the total nonrefractory particulate mass and chemical composition to within $\pm 20 \%$ (e.g. Drewnick et al., 2003; Hogrefe et al., 2004; Takegawa et al., 2005; Zhang et al., 2005a; Quinn et al., 2006) including the fractions of different types of organic species (Zhang et al., 2005c; Takegawa et al., 2006; Kondo et al., 2007; Docherty et al., 2008; Aiken et al., 2009). Such ensemble data comparisons suggest that the different single particle vaporization event types do not result in a significant bias between the AMS-measured and actual ambient nonrefractory mass concentrations and compositions.

\subsection{Characterization of single particle chemical composition}

Single particle mass spectra were analyzed using the standard AMS approach based on a priori information of the fragmentation patterns of inorganic and organic species (Allan et al., 2003). This technique identifies non-refractory inorganic species (ammonium, nitrate, sulfate, and chlorides) and separates their mass spectral signals from particulate organic signals.

Single particle measurements of ammonium with the AMS were subject to high noise due to interference from background water vapor within the AMS chamber. Despite this challenge, ammonium was measured with reasonable accuracy for single particles with large amounts of ammonium nitrate, sulfate, and/or chloride ( $\sim 50 \%$ by mass). For smaller levels, the $\mathrm{NH}_{4}$ content of the single particles can be systematically underestimated. As a result, in most cases the uncertainty in $\mathrm{NH}_{4}$ is the largest source of scatter in the calculation of the single particle mass fractions. Full neutralization of nonrefractory inorganic species has been previously observed during the dry season in the MCMA (Moya et al., 2003) and the LS-ToF-AMS ensemble average measurements at $\mathrm{T} 1$ indicated that the nonrefractory inorganics present were fully neutralized. Based on these observations and on mass balance, we will assume that the single particle inorganics were in the form of $\mathrm{NH}_{4} \mathrm{NO}_{3},\left(\mathrm{NH}_{4}\right)_{2} \mathrm{SO}_{4}$, and $\mathrm{NH}_{4} \mathrm{Cl}$. The $\mathrm{NH}_{4}$ content of each single particle is therefore calculated from the measured single particle mass of nitrate, sulfate, and chloride, except for the results presented in Sect. 4.1.3.

The mass spectra of the organic fraction are more complex and require more rigorous deconvolution techniques. Because the single particle mass spectra are analogous to AMS ensemble mass spectra, they are, in principle, amenable to more complicated mass spectral deconvolution techniques currently being developed and applied to standard AMS mass spectra. These techniques include principle component analysis (PCA) (Zhang et al., 2005b) and positive matrix factorization (PMF) (Lanz et al., 2007a, b; Ulbrich et al. 2009). Two of the major types of organic species identified through the use of these multivariate analysis techniques are hydrocarbon-like organic aerosol (HOA) and oxygenated organic aerosol (OOA). HOA particles are strongly correlated with primary aerosol originating from fossil fuel combustion sources and are associated with $m / z=57$ (mostly $\mathrm{C}_{3} \mathrm{H}_{9}^{+}$) in AMS spectra. The OOA particles are most likely secondary organic aerosol (SOA) formed in the atmosphere through the condensation of oxidized low vapor pressure organic gases and are associated with $m / z=44$ (mostly $\mathrm{CO}_{2}^{+}$) in AMS spectra.

Our initial chemical analysis approach was to conduct PMF analysis on the ensemble aerosol mass spectra (MS Mode), ensemble PTOF distribution mass spectra, and single particle mass spectra. However, due to low $\mathrm{S} / \mathrm{N}$ for 

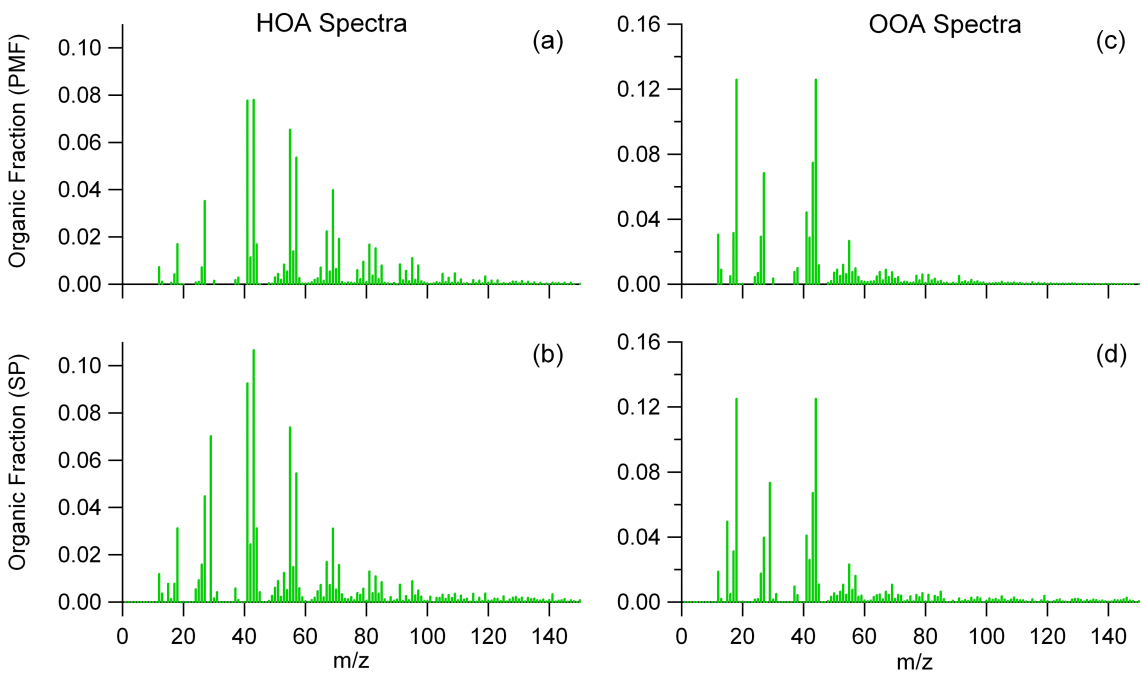

Fig. 5. Average HOA and OOA organic mass spectra obtained from ambient ensemble measurements using PMF analysis (upper region, plots (a) and (c)) and two-component PCA-derived analysis for average prompt single particles (lower region plots (b) and (d)).

signal at each $\mathrm{m} / \mathrm{z}$ and low single particle counting statistics for the single particle data we settled on the simple and published method (PCA-derived empirical formula) for apportioning the ensemble PTOF mode and single particle organic fractions into the two dominant OOA and HOA components using $m / z=44$ and 57, respectively (Zhang et al., 2005b). For the ensemble average mass spectra obtained in MS mode, PMF analyses are used to identify the different organic components. Comparisons between results from PMF and the 2component PCA-derived method indicate that both of these methods derive very similar HOA and OOA factors from the ensemble organic aerosol mass spectra measured with the LS-ToF-AMS, which account for $>90 \%$ of the variance in the ensemble data.

The PCA-derived average single particle mass spectra for HOA and OOA fractions compare well with the ensemblederived PMF mass spectra. Figure 5 shows the average mass spectra for the HOA and OOA components as determined by PMF for the MS mode ensemble data (top panels; a and $\mathrm{b}$, respectively) and the corresponding PCA-derived average single particle mass spectra for HOA and OOA (bottom panels; $\mathrm{c}$ and d, respectively). The averaged single particle mass spectra shown in Fig. 5c and d were obtained by applying the PCA-derived empirical formula to all prompt single particles to classify the organic fraction as HOA and OOA and then the particles were filtered for organic mass fractions greater than $50 \%$ and HOA or OOA fractions greater than $90 \%$, selecting $\sim 400$ particles for each spectrum. Visual comparison indicates that the average HOA mass spectra and average OOA mass spectra obtained with the two different deconvolution methods are similar. Thus, comparisons between the HOA and OOA factors determined using the PCA-derived and PMF methods in aerosol loading, size distribution, and single particle measurements are meaningful.
PMF analysis of the MCMA ensemble (MS mode) organic aerosol data with more than 2 factors indicates the presence of a biomass burning organic aerosol (BBOA) factor and a minor Fomblin oil factor, in addition to HOA and OOA factors. Thus, it is possible that the single particle HOA and OOA components may have some contributions from biomass burning source aerosols. As discussed in Sect. 4, single particle chemical filters were used to identify single particles with significant influence from these different sources.

A comparison of three OOA and three HOA prompt single particle mass spectra is shown in Fig. 6. The particles were randomly chosen from the sampled particles with the criterion that the particle contains a high organic mass fraction consisting of either OOA or HOA. This figure demonstrates the following features: a) single particles with $d_{\mathrm{o}} \sim 350 \mathrm{~nm}$ $\left(300<d_{\mathrm{va}}<700 \mathrm{~nm}\right.$; note, $d_{\mathrm{va}}$ is a function of particle density) exhibit relatively high $\mathrm{S} / \mathrm{N}$ for all $\mathrm{m} / z$ signals $<100 \mathrm{amu}$; b) HOA and OOA particles are readily distinguishable and exhibit characteristic peaks for HOA $(m / z=57)$ and OOA $\left(\mathrm{m} / z=44\right.$ and 18); and c) single particles with $d_{\mathrm{o}} \sim 200 \mathrm{~nm}$ (or smaller) $\left(250<d_{\mathrm{va}}<350 \mathrm{~nm}\right)$ have low $\mathrm{S} / \mathrm{N}$ at most $\mathrm{m} / \mathrm{z}^{\prime}$ 's and the single particle mass spectra exhibit only a few characteristic $\mathrm{m} / \mathrm{z}$ ion signals. Thus, the size detection limit for single particle chemical ion and optical measurements was approximately the same for the instrument in the present MILAGRO study.

\subsection{Detection of externally mixed particles}

A direct demonstration of how the physical and chemical information obtained with the LS-ToF-AMS can provide mixing state information is a case when two particles entered the AMS during one chopper opening, recorded at 05:35 LT on 

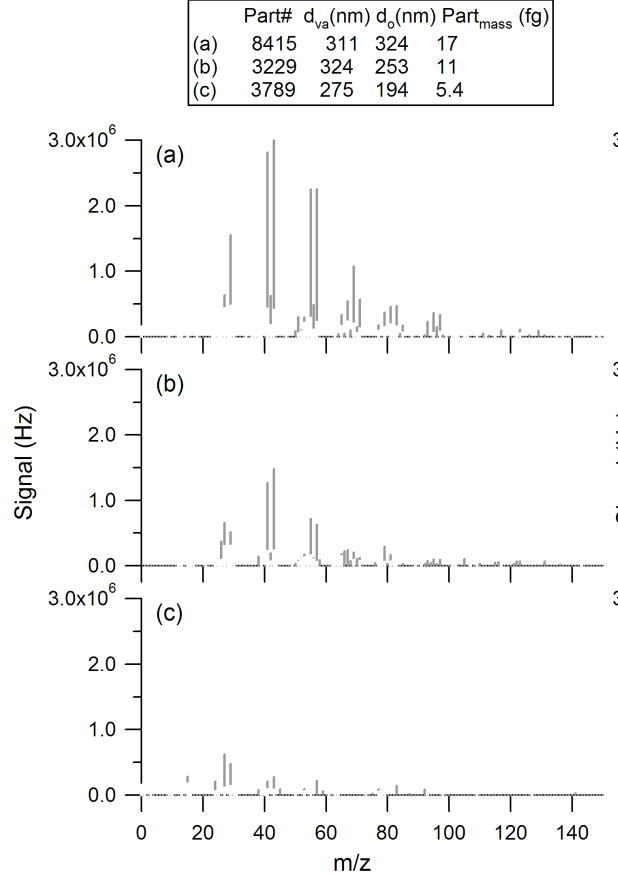

Part\# $d_{10}(n m) d_{0}(n m)$ Part $(f g)$ (d) $\begin{array}{rlll}1082 & 670 & 352 \quad 43\end{array}$ (e) $11336 \quad 365 \quad 265 \quad 13$ (f) $\begin{array}{llll}255 & 324 & 201 & 6.8\end{array}$
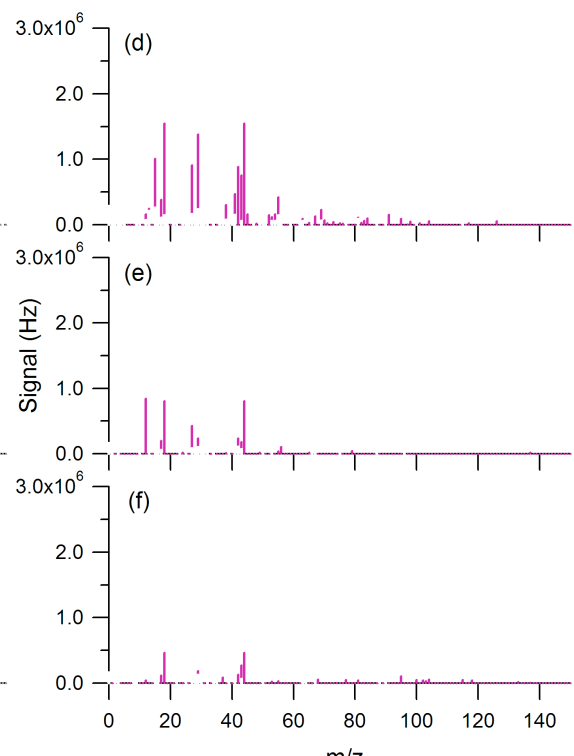

Fig. 6. Six single particle mass spectra obtained for three different sized organic particles $\left(d_{0} \sim 200,250\right.$, and $\left.350 \mathrm{~nm}\right)$ predominately composed of HOA ((a)-(c)) and OOA ((d)-(f)) components. Particle $d_{\mathrm{va}}, d_{0}$, and mass are shown in the insert.

27 March during the morning rush hour. (Under the ambient particle concentrations observed during the experiment, we expect such a two-particle coincidence to occur $\sim 1 \%$ of the time). The top panel of Fig. 7 shows the scattered light pulses from the two particles as a function of time-of-flight, with $t_{0}$ defined by the opening of the chopper slit. The middle panel shows the corresponding chemical ion signals. The lower panel displays the mass spectrum for each of the sampled particles.

The prompt single particle mass spectra in the bottom of Fig. 7 clearly show that the chemical compositions of the two sampled particles are distinct. The nonrefractory component of particle 1 is composed of $100 \%$ organic material. The largest mass spectrum component is at $m / z=57$, characteristic of an HOA-dominated particle. The nonrefractory component of particle 2 is a mixture of oxygenated organics, ammonium nitrate, and ammonium sulfate, approximately in equal amounts. Table 1 summarizes the measured chemical and physical properties for these two particles.

Combining the chemical and physical information collected by the LS-ToF-AMS from these two particles tells a self-consistent story. Particle 1 was composed of hydrocarbon-like organic (HOA) matter and exhibited a low effective density. The low effective particle density is consistent with hydrocarbon-like organic (e.g. lubricating oil) densities as well as possibly indicating that Particle 1 was aspherical due to an underlying fractal-like black carbon core. Thus, particle 1 is classified as a HOA particle, likely generated from a local combustion source. In contrast, particle 2 was composed of highly oxidized inorganic and organic matter and exhibited a relatively high effective density consistent with the particle's significant inorganic composition. Particle 2 is classified as an internally mixed accumulation mode particle that likely had undergone significant atmospheric processing prior to detection with the LS-ToF-AMS. The simultaneous observation of these two chemically distinct particles illustrates the capabilities of the LS-ToF-AMS technique to provide information about the mixing state of submicron aerosol particles.

\section{MCMA Ambient Aerosol Properties: connections between single particle and ensemble aerosol measurements}

We have chosen to restrict the discussion in this section to a detailed analysis of the 2956 prompt vaporization single particle events. As discussed in Sect. 3, particle bounce affects the degree to which the nonrefractory components in delayed/null single particle vaporization events are detected in a single PTOF cycle. We note that by focusing on the data obtained from the prompt vaporization particle events only, we restrict the single particle analysis to a subset of ambient aerosol particles (i.e. $23 \%$ of the sampled ambient particles with $d_{\mathrm{va}}>350 \mathrm{~nm}$ ). Therefore, the prompt single particle results alone do not describe the entire atmospheric 
Table 1. Single particle properties of two externally mixed particles shown in Fig. 7.

\begin{tabular}{lcccccccc}
$\begin{array}{l}\text { Particle } \\
\text { Property }\end{array}$ & $\begin{array}{c}\text { Velocity } \\
(\mathrm{m} / \mathrm{s})\end{array}$ & $d_{\mathrm{va}}(\mathrm{nm})$ & $\begin{array}{c}d_{\mathrm{o}} \\
(\mathrm{nm})\end{array}$ & $\begin{array}{c}\text { Total mass } \\
\text { measured by mass } \\
\text { spectrometer }(\mathrm{fg})\end{array}$ & $\begin{array}{c}\text { Chemical } \\
\text { density } \\
\left(\mathrm{g} / \mathrm{cm}^{3}\right)^{\mathrm{a}}\end{array}$ & $\begin{array}{c}\text { Optical } \\
\text { density } \\
\left(\mathrm{g} / \mathrm{cm}^{3}\right)^{\mathrm{b}}\end{array}$ & $\begin{array}{c}\text { Predicted } \\
\text { physical } \\
\text { diameter } \\
(\mathrm{nm})^{\mathrm{c}}\end{array}$ & $\begin{array}{c}\text { Calculated } \\
\text { total mass } \\
(\mathrm{fg})^{\mathrm{d}}\end{array}$ \\
\hline Particle \#1 & 106 & 287 & 301 & 18.2 & 0.9 & 0.95 & 326 & 13.64 \\
Particle \#2 & 94 & 446 & 263 & 13.0 & 1.48 & 1.70 & 211 & 16.14 \\
\hline
\end{tabular}

\footnotetext{
${ }^{\text {a }}$ Chemical density calculated with assumed bulk densities for organic and inorganic nonrefractory components.

${ }^{\mathrm{b}}$ Optical density $=$ Effective density $=d_{\mathrm{va}} / d_{\mathrm{O}}$.

${ }^{\mathrm{c}}$ Predicted physical diameter calculated based on the assumption of a spherical particle with a total mass equal to that measured by the mass spectrometer.

${ }^{\mathrm{d}}$ Calculated total mass $=m_{\mathrm{p}}=\pi / 6 \times d_{\mathrm{o}}^{2} \times d_{\mathrm{va}}$.
}

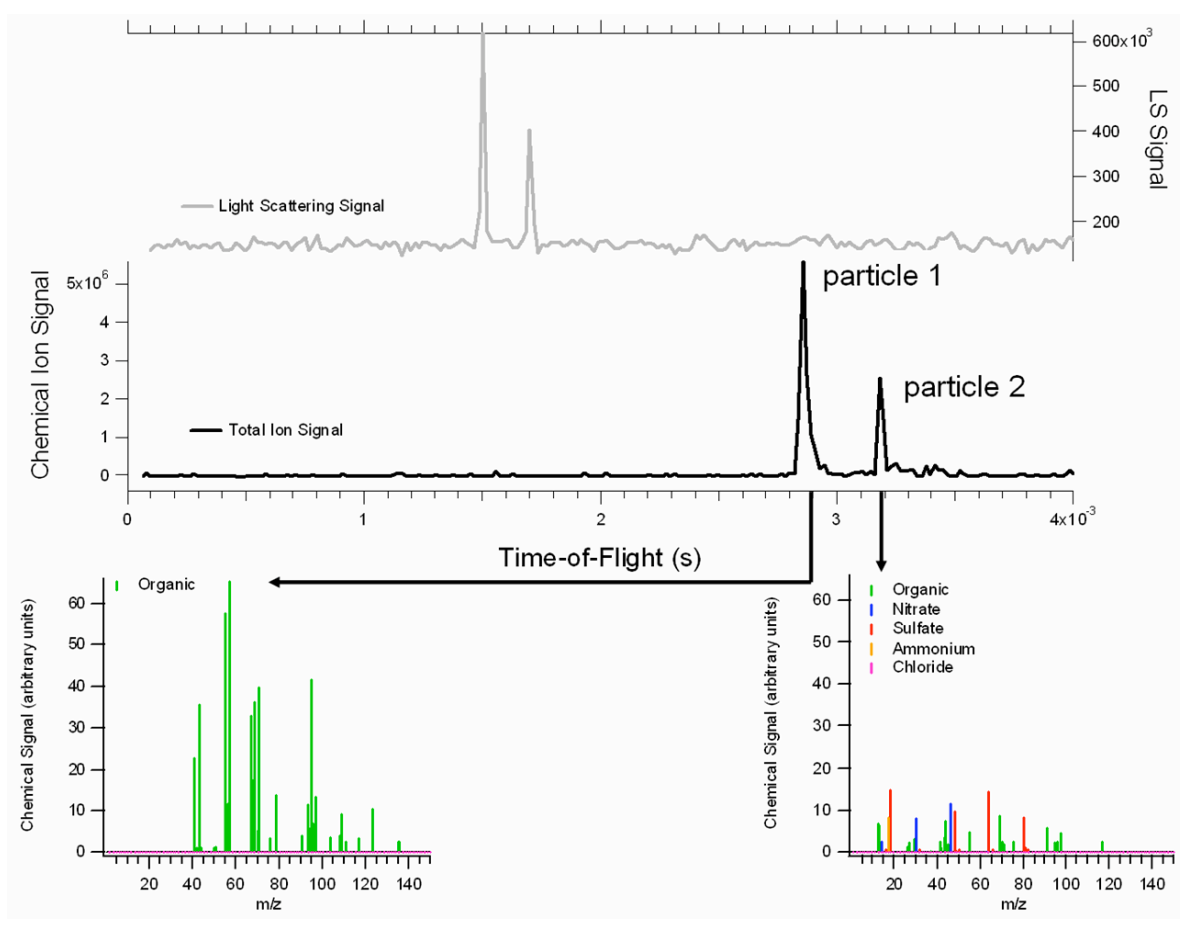

Fig. 7. Light scattering signals (upper panel) and chemical ion signals (middle panel) as a function of particle time-of-flight for a single chopper cycle in which two particles entered the LS-ToF-AMS. The lower panel displays the mass spectrum of each particle.

submicron aerosol particle population in the MCMA. However, a unique feature of the LS-ToF-AMS is that it provides an interleaved dataset of ensemble average as well as single particle measurements. Thus, information gathered from the analysis of the prompt single particles measured can be compared and combined with the observations of the ensemble aerosol to provide a more complete description of the mixing state and atmospheric transformations of the ambient submicron aerosol. Trends in the speciated mass concentrations and size distributions for the ensemble aerosol are shown in Figs. 8 and 9, respectively.
The organic aerosol chemical composition of the prompt single particles was apportioned into HOA and OOA components according to the $m / z=57$ and $m / z=$ ]44 ion signals as described in Sect. 3.4. To account for other potential types of organic particles, chemical filters were constructed to identify and remove particles that contained significant contributions from other types of organic species. For example, several single particles were observed that were dominated by unique organic $m / z$ signals at $m / z=69,119$, and 169 . The spectra, not shown, matched previous examples of high temperature lubricating oil (such as Fomblin pump oil), likely from an instrument pump used at the T1 site for sampling 


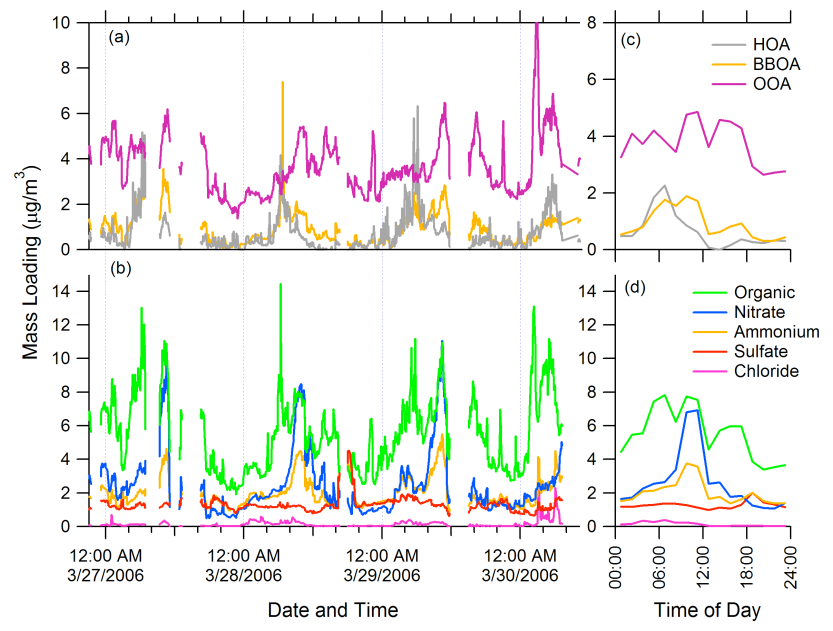

Fig. 8. Average ensemble mass concentrations (measured in MS mode) as a function of sampling time. (a) Organic components obtained from PMF analysis - OOA, BBOA, and HOA. (b) Chemical components obtained from traditional AMS fragmentation patterns - organic, nitrate, sulfate, ammonium, and chloride. Average diurnal cycles, for the full 75 sampling period, of each chemical component are displayed in plots (c) and (d).

purposes. Fifteen Fomblin particles $(0.5 \%$ of the prompt particles) were identified during the 75-h sampling period and agree qualitatively with the minor factor for Fomblin determined from the multiple factor PMF. These particles were removed from further analysis.

Specific attention was also paid to the identification of single particle mass spectral markers characteristic of biomass burning sources. Several published accounts of strong biomass burning influence in the Mexico City basin before MILAGRO (Bravo et al., 2002; Salcedo et al., 2006; Molina et al., 2007) and during the MILAGRO study suggest that biomass burning is an important source of particles in this region (Yokelson et al., 2007; Stone et al., 2008; DeCarlo et al., 2008; Moffet et al., 2008a; Aiken et al., 2009). However, the meteorological conditions and co-located measurements of biomass burning markers at T1 (Stone et al., 2008) are consistent with lower BBOA concentrations during the period of LSSP single particle sampling. While the biomass burning influence may have been lower during this time period, PMF analysis of the MCMA ensemble (MS mode) organic aerosol still identified a BBOA factor, shown in Fig. 8. The BBOA factor mass spectrum is distinct from the HOA and OOA mass spectra in that it contains significant signal at $m / z$ 's 60 and 73. As described in DeCarlo et al. (2008), $m / z=60$ and 73 are reasonable markers for biomass burning aerosol in Mexico City.

To investigate potential signatures of biomass burning in the single particle mass spectra, a filter based on $\mathrm{m} / \mathrm{z}$ marker peaks at 39 (potassium) and 60 and 73 (levoglucosan and related species) was used (DeCarlo et al., 2008; Alfarra et al., 2007; Schneider et al., 2006). Levoglucosan

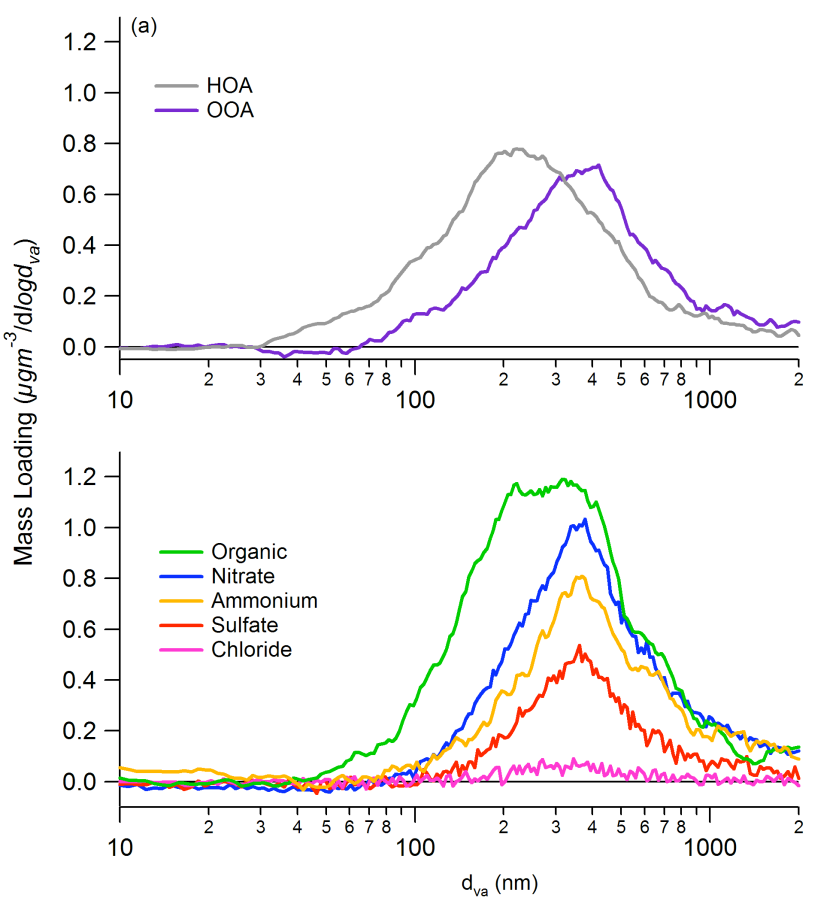

Fig. 9. Average ensemble mass distributions (measured in PTOF mode) as a function of vacuum aerodynamic diameter $\left(d_{\mathrm{va}}\right)$ for (a) HOA and OOA components and (b) organic, nitrate, sulfate, ammonium, and chloride.

(1,6-anhydro- $\beta$-D-glucopyranose), the pyrolysis product of cellulose, is a marker for the combustion of biomass materials (Simoneit, 2002). In total, only 139 single particles were identified as having significant BBOA content $(\sim 5 \%$ of the prompt particles), suggesting little biomass burning influence in the measured prompt particles. The PMF analysis of the MS mode data suggests that the BBOA factor can account for almost $30 \%$ of the organic PM at times during the sampling period (refer to Fig. 8). It is useful to note that the number of detected single particles with significant BBOA content may have been suppressed relative to other prompt particles because (1) the potassium ion signal at $m / z=39$, which is a biomass burning marker, are formed via a different ionization process (i.e. surface ionization), (2) levoglucosan markers at $m / z=60$ and 73 exhibited low $\mathrm{S} / \mathrm{N}$ for smaller particles as discussed in Sect. 3.4, (3) the biomass burning particles were internally mixed with other particulate material (i.e. counted as OOA or HOA), and (4) biomass burning particles may fall below the optical detection limit due to small sizes or nonspherical and absorbing refractory components which would likely result in smaller observed $d_{\mathrm{va}}$ 's and lower scattered light signals. Further characterization studies of the LS-ToF-AMS response to biomass burning particles are necessary before definitive conclusions about biomass burning source contributions can be drawn from the single particle data. 


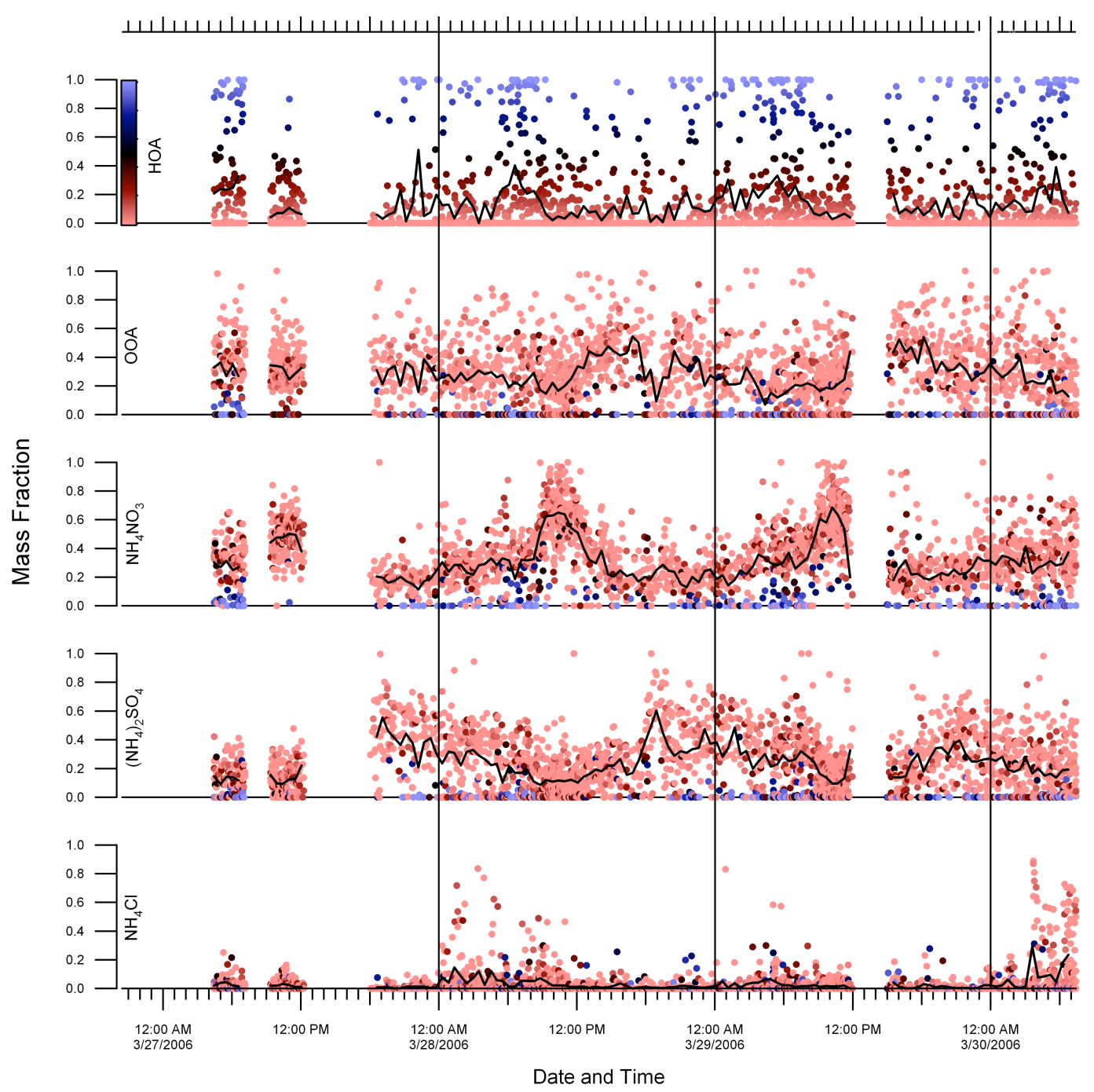

Fig. 10. Time series of $\mathrm{NH}_{4} \mathrm{Cl},\left(\mathrm{NH}_{4}\right)_{2} \mathrm{SO}_{4}, \mathrm{NH}_{4} \mathrm{NO}_{3}$, OOA, and $\mathrm{HOA}$ single particle mass fractions. Data points are colored by $\mathrm{HOA}$ mass fraction as indicated in the upper left.

The 139 single particles with significant BBOA composition were not included in the HOA and OOA analysis. With these particles removed, the reconstructed organic (HOA+OOA) accounted for $93 \%\left(R^{2}=0.84\right)$ of the measured prompt single particle organic mass, suggesting that HOA and OOA give a reasonable, but not complete, description of the organics at $\mathrm{T} 1$.

\subsection{Mixing state of MCMA aerosol}

The fractional compositions of prompt single particles measured during the 75-h single particle sampling period are plotted in Fig. 10. The data are presented in five panels showing the mass fractions of $\mathrm{HOA}, \mathrm{OOA}, \mathrm{NH}_{4} \mathrm{NO}_{3},\left(\mathrm{NH}_{4}\right)_{2} \mathrm{SO}_{4}$, and $\mathrm{NH}_{4} \mathrm{Cl}$ for each particle, plotted as a function of the local sampling time. Each panel shows the measured single particle mass fraction of the designated chemical component. That is, every particle is plotted in each panel and can be classified into different particle types by the measured nonrefractory chemical compositions (i.e. mass fractions). The solid black trace plotted in each panel is the 30-min average of the corresponding prompt single particle mass fractions. The vertical black lines denote midnight on each of the sample days.

The color scheme for the points in all panels of Fig. 10 indicates the HOA content of each particle. Thus, particles colored blue have high-HOA content (HOA mass fraction $>0.90$ ), particles colored red have low-to-zero-HOA content (HOA mass fraction $<0.10$ ), and particles colored purple (i.e. red + blue) have intermediate-HOA content $(0.10<$ HOA mass fraction $<0.90$ ). 


\subsubsection{Trends of internally mixed aerosol species}

The most prominent feature of Fig. 10 is the observation that the majority of the prompt single particles measured were internal mixtures of more than one chemical component. This is evident from the lack of a substantial number of particles plotted in Fig. 10 with mass fractions of any single component equal to 1 . This observation is important as it provides insights into the rate of atmospheric processing of accumulation-mode particles in the Mexico City basin and has implications for better understanding the fate and atmospheric effects of primary particles. These prompt single particle observations of significant internal mixing of Mexico City aerosol provide a consistent explanation for why the average accumulation mode mass distributions for organic (OOA) and inorganic components shown in Fig. 9 exhibit similar size distributions during the sampling period.

Figure 10 shows that the chemical compositions (highlighted by the $30 \mathrm{~min}$ averages) of the single particles were dominated by different chemical components at different times of the day. The most obvious example occurs during the morning ( $\sim 1 \mathrm{~h}$ after sunrise). At this time, the $\mathrm{NH}_{4} \mathrm{NO}_{3}$ mass fraction of all prompt single particles rapidly increased reaching a peak (average of $\sim 0.6$ ammonium nitrate mass fraction of the measured nonrefractory particulate mass) between 10:00-11:00 LT before rapidly declining in the early afternoon. The fact that all prompt single particles measured between 09:00-12:00 LT contained $\mathrm{NH}_{4} \mathrm{NO}_{3}$ suggests rapid gas phase photochemistry and subsequent condensation of secondary species, such as nitric acid, onto pre-exisiting particles. The MCMA atmosphere contains high concentrations of gas phase $\mathrm{NH}_{3}(>35 \mathrm{ppb}$ in the early morning) (Zheng et al., 2008). Thus, nitric acid formed from the reaction of $\mathrm{NO}_{2}$ and photochemically-produced $\mathrm{OH}$ radicals can readily form ammonium nitrate and condense on pre-exisitng particles in the early morning hours at $\mathrm{T} 1$ when the temperature was low. As the temperature increased in the late morning and early afternoon, the equilibrium of $\mathrm{NH}_{4} \mathrm{NO}_{3}$ favors the dissociation back to $\mathrm{NH}_{3}$ and $\mathrm{HNO}_{3}$ (Zheng et al., 2008). The ensemble particulate $\mathrm{NO}_{3}$ mass concentration time trends measured in the MS mode show similar trends of increased mass between 09:00-12:00 LT in the morning (refer to Fig. 8.). In addition, the PTOF mode ensemble $\mathrm{NO}_{3}$ size distributions obtained during these morning hours (not shown, but similar to the average distributions shown in Fig. 9) are broad (i.e. extend below the small size cut-off, $\sim 350 \mathrm{~nm} d_{\mathrm{va}}$, of the single particle mode) and consistent with the gas-to-particle condensation of $\mathrm{NO}_{3}$ observed in the prompt single particles. Taken together, the single particle and ensemble results indicate that condensation of secondary ammonium nitrate provides an important means of producing internal mixtures in the morning.

The prompt single particle OOA mass fraction increased gradually during the daylight hours, reaching a peak (average of $\sim 0.4 \mathrm{OOA}$ mass fraction of the measured nonrefractory particulate mass) in the middle of the afternoon. Significant formation of secondary organic aerosol in the MCMA region has been previously reported (Volkamer et al., 2006, 2007; Kleinman et al., 2008; Stone et al., 2008; Hennigan et al., 2008; Paredes-Miranda et al., 2009; Herndon et al., 2008; DeCarlo et al., 2008; Fast et al., 2009; Aiken et al., 2009). Between 15:00-18:00 LT, OOA was observed to condense onto nearly all prompt single particles, indicating gasto-particle condensational growth due to secondary organic aerosol photochemistry. The organic mass concentrations from the MS mode and the organic size distrubtions from the PTOF mode both show trends that are dominated by the OOA component during this afternoon time period. Thus, as in the case of $\mathrm{NO}_{3}$, the gas-to-particle condensation of OOA observed for the prompt single particles by the LS-ToF-AMS in the afternoon appears to reflect the behaviour of the ambient aerosol population.

Sulfate has been reported to be a major component of $\mathrm{PM}_{2.5}$ in the MCMA (Salcedo et al., 2006; Johnson et al., 2005, 2006; Querol et al., 2008; DeCarlo et al., 2008; Kleinman et al., 2008). In the MCMA, $\mathrm{SO}_{2}$ has significant anthropogenic (industrial regions concentrated in the northwest) and natural (the active Popocatepetl volcano in the southwest) sources, though given the general lack of spatial variability in particulate sulfate concentrations, sulfate is typically attributed to regional-scale atmospheric processing (Querol et al., 2008; DeCarlo et al., 2008). The prompt single particle $\left(\mathrm{NH}_{4}\right)_{2} \mathrm{SO}_{4}$ mass fractions were highest during the evening and overnight periods. The prompt single particle measurements at $\mathrm{T} 1$ also included one instance of a peak in $\left(\mathrm{NH}_{4}\right)_{2} \mathrm{SO}_{4}$ during a strong $\mathrm{SO}_{2}$ plume event on 28 March at 19:00 LT. Back trajectories for the time period indicate that the air was arriving at $\mathrm{T} 1$ directly from the northwest. The Tula power plant refinery complex is located $\sim 50 \mathrm{~km}$ to the northwest of $\mathrm{T} 1$ and has been shown to emit high concentrations of $\mathrm{SO}_{2}$ into the MCMA region (Johnson et al., 2006; Kleinman et al., 2008; DeCarlo et al., 2008; Fast et al., 2007; Querol et al., 2008). Co-located gas phase measurements at $\mathrm{T} 1$ confirmed that the plume measured at this time contained elevated levels of $\mathrm{SO}_{2}(\sim 8 \mathrm{ppb})$ suggesting that the plume was a result of point source emissions rather than regionalscale processing. During the plume, all of the prompt single particles measured had $\left(\mathrm{NH}_{4}\right)_{2} \mathrm{SO}_{4}$ mass fractions of $\sim 0.70$ when compared with the total measured nonrefractory particulate mass, suggesting that gas phase $\mathrm{SO}_{2}$ oxidation followed by gas-to-particle condensation or heterogeneous oxidation of $\mathrm{SO}_{2}$ to $\mathrm{SO}_{4}^{2-}$ occurred within the plume as it was advected to the $\mathrm{T} 1$ site. The ensemble particulate sulfate mass concentrations and size distributions during this plume event are consistent with the prompt single particle observations.

In each of these three cases, the LSSP mode of the LSToF-AMS provides direct evidence that a subset of ambient aerosol particles (prompt single particles represent $23 \%$ of sampled ambient particles with $d_{\mathrm{va}}$ greater than $350 \mathrm{~nm}$ ) are experiencing gas-to-particle condensational growth due 


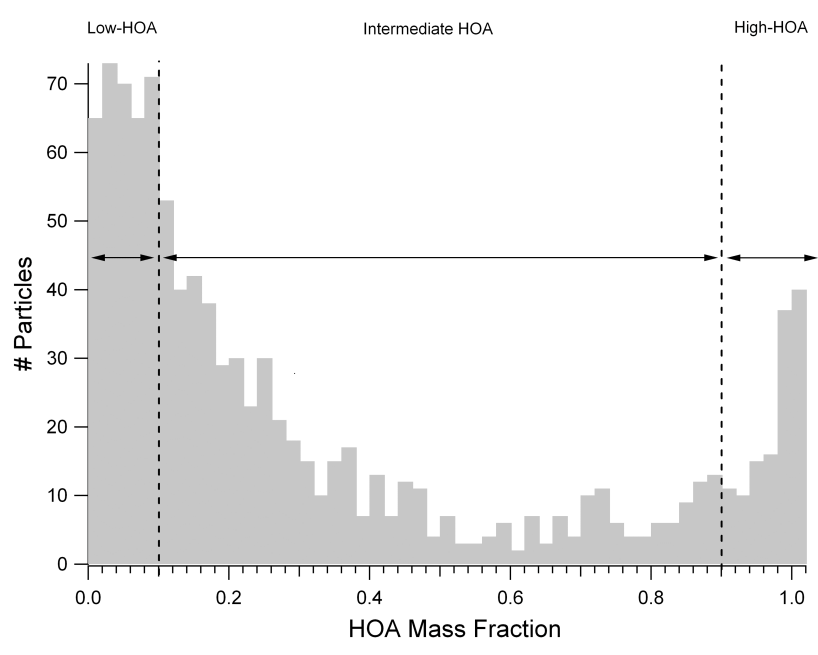

Fig. 11. Particle counts as a function of HOA mass fraction.

to secondary inorganic and organic species. The corresponding MS and PTOF mode data provide supporting evidence that these prompt single particle observations reflect atmospheric transformations that are occurring on the total ambient aerosol. These observations of internal mixing due to gas-to-particle condensation are consistent with the photochemistry in the MCMA being efficient (beginning soon after sunrise) and significantly impacting the ambient aerosol mass loadings and chemical composition (Volkamer et al., 2006; de Gouw et al., 2008; Kleinman et al., 2008). Further, the LS-ToF-AMS prompt single particle observations of gas-to-particle condensation of OOA is consistent with the oxidized organic aerosol (OOA) component measured by AMS instruments corresponding to secondary organic aerosol (SOA) (Zhang et al., 2005a, c; Takegawa et al., 2006; Volkamer et al., 2006; Kondo et al., 2007; Herndon et al., 2008; Aiken et al., 2009).

\subsubsection{Primary HOA particles and their processing}

While the sampled prompt single particles were typically internally mixed with evidence for gas-to-particle processes controlling their chemical compositions, there are several examples of external mixtures of different particle types with chemically distinct compositions in Fig. 10. One clear example is a subset of single particles with high HOA mass fractions which were observed each day during the early morning and late evening time periods.

The HOA component measured by the AMS has been shown to be correlated with primary emissions (Zhang et al., 2005b; Canagaratna et al., 2007). Ensemble HOA data at T1, obtained while operating the instrument in MS mode, show that the HOA factor was strongly correlated with measurements of $\mathrm{CO}$ and elemental carbon (EC), markers associated with primary emissions in Mexico City. LS-ToF-AMS single particle observations of external mixing of carbonaceous particles in MCMA are consistent with the results from Johnson et al. (2005), Adachi and Buseck (2008), and Moffet et al. (2008a). Johnson et al. (2005) used filter-based single particle imaging and chemical analyses during the MCMA-2003 Field Campaign and reported observing externally mixed, traffic-related particulate emissions consisting of soot particles apparently coated with unburned lubricating oil. Moffet et al. (2008a) observed particles classified as "EC" with the ATOFMS (at the T0 site during MILAGRO) that contained significant elemental carbon composition during the early morning and little nitrate (secondary inorganic marker). The "EC" particles reported by Moffet et al. (2008a) were described as mainly "freshly emitted vehicle particles". Both of these studies investigated and reported on evidence for atmospheric "aging" of these particle types during the day. The LS-ToF-AMS is chemically sensitive to unburned lubricating oil, the major nonrefractory component of vehicle emissions (Canagaratna et al., 2004; Sakurai et al., 2003). The combination of the external mixing state, HOA-dominated chemical composition, diurnal variations in number concentration that correspond with the local rush hours, and correlation with previous observations identifies these particles as primary, traffic-related particles. Tracking these HOAdominated single particles through the diurnal cycle provides an approach to characterizing primary, combustion-related particles and their subsequent atmospheric transformations.

The prompt single particles in Fig. 10 were separated into the following categories in accord with the color scheme of the particles: (1) High-HOA particles considered unprocessed primary particles with HOA measured nonrefractory particulate mass fraction $\geq 0.90$, (2) Intermediate-HOA particles considered processed primary particles with HOA mass fractions between 0.10 and 0.90 , and (3) Low-HOA particles with HOA mass fractions $<0.10$ and not definitively linked to primary (e.g. local combustion) sources. The histogram of measured prompt single particle HOA mass fractions is shown in Fig. 11. Single particles with HOA mass fractions equal to zero were not included in the histogram. The histogram represents $35 \%$ of the total prompt particle sample. The histogram reveals a group of single particles peaking at HOA mass fraction $\sim 1.0$ and a larger group centered at HOA mass fraction $\sim 0.05$.

To characterize the mixing state of the prompt particles, the diurnal trends in the single particle number and number fraction of high-HOA, intermediate-HOA and low-HOA (including HOA mass fractions equal to zero) particle types are displayed in Fig. 12a as a stacked plot and Fig. 12b, respectively. The majority (60-80\%) of the prompt single particles detected were classified as low-HOA particles throughout the average day, characteristic of internally mixed (e.g. processed) accumulation mode particles. The number of particles in all categories decreased between 11:00-13:00 LT due to dilution caused by the rising boundary layer.

The prompt single particle data show that the number and number fraction of high-HOA and intermediate-HOA 

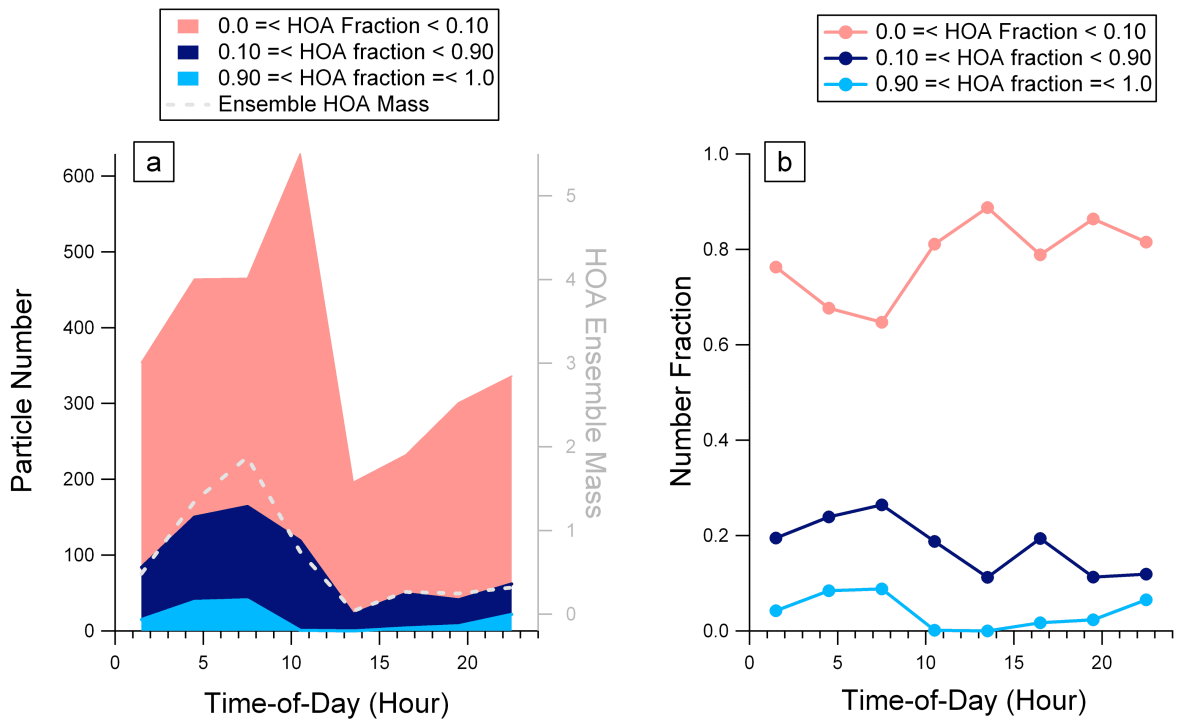

Fig. 12. Time trends in the (a) measured number and (b) number fraction of high-HOA, intermediate-HOA, and low-to-zero-HOA particles.

particles were largest in the early morning (04:30-07:30 LT), accounting for $\sim 30-40 \%$ of the prompt particles. The maximum in number and number fraction of high-HOA particles ( $\sim 10 \%$ of the prompt particles) likely corresponds to local combustion source emissions that build up in the atmosphere during the early morning hours. This is consistent with the meteorological conditions of a low boundary layer (inhibiting dilution of local emissions), low photochemical activity (i.e. low production of secondary condensable species), typical morning rush hour traffic in MCMA (i.e. large primary source of combustion-related particles), and the ensemble average mass loadings of HOA shown in Fig. 8. A second peak in the number fraction of intermediate-HOA particles is observed in the afternoon ( 17:00 LT), likely corresponding to the afternoon rush hour. The externally mixed highHOA particles reappear at this time and steadily increase in number and number fraction after the sun has gone down ( $\sim 20: 00 \mathrm{LT})$ and through the night into the early morning.

The number and number fraction of high-HOA particles decreased to zero after sunrise ( 09:00 LT) while the number of intermediate-HOA particles remained relatively constant $(\sim 20 \%)$. The disappearance of high-HOA particles in the late morning (while the boundary layer was still relatively low, but after the sun had risen) suggests that the highHOA particles were rapidly coated with secondary oxidation products, such as ammonium nitrate. Given the distance of the likely source at $\mathrm{T} 1$ of the primary, high-HOA particles (the highway $\sim 1 \mathrm{~km}$ away) and the average wind speed and direction, a rough estimate suggests that these primary HOA particles became internally mixed particles (i.e. were coated with photochemical products) in $\sim 15-30$ min during the mid to late morning (09:00-12:00 LT). To illustrate the connection between single HOA particles and ensemble HOA measurements, we include the diurnal trend for ensemble HOA mass as the dashed grey line in Fig. $12 \mathrm{a}\left(\mu \mathrm{g} / \mathrm{m}^{3}\right.$ plotted on the right-hand axis). The sum of the high-HOA and intermediate-HOA single particles follows a diurnal trend that is similar to the ensemble HOA mass loading data. The fact that the measured ensemble HOA mass loadings had a similar diurnal trend and does not go to zero, as does the number of high-HOA single particles, supports the prompt single particle observations that the primary HOA particles were rapidly becoming internally mixed (i.e. coated) with secondary species during the day.

The LS-ToF-AMS deployed during the MILAGRO study was limited by a low single particle sampling duty cycle and a high single particle detection limit. The number fractions of prompt particles with measurable HOA composition provide insight into the mixing state of a subset of ambient aerosol particles. A comparison between the size distributions for single particles in Fig. 4a and for the HOA/OOA ensemble PTOF in Fig. 9a shows that the LS-ToF-AMS LSSP mode deployed for this study did not measure most (by number or mass) of the HOA containing particles. The number concentration of externally mixed HOA-dominated single particles was likely much higher in total than observed and reported here.

\subsubsection{High chloride content single particles}

The second case of a chemically distinct subset of single particles evident in Fig. 10 was the presence of particles with high chloride content observed between 00:00 10:00 LT each day. During these times, $\sim 10 \%$ of the prompt single particles sampled had $\mathrm{NH}_{4} \mathrm{Cl}$ mass fractions $>0.10$. These single particle observations correspond with spikes 

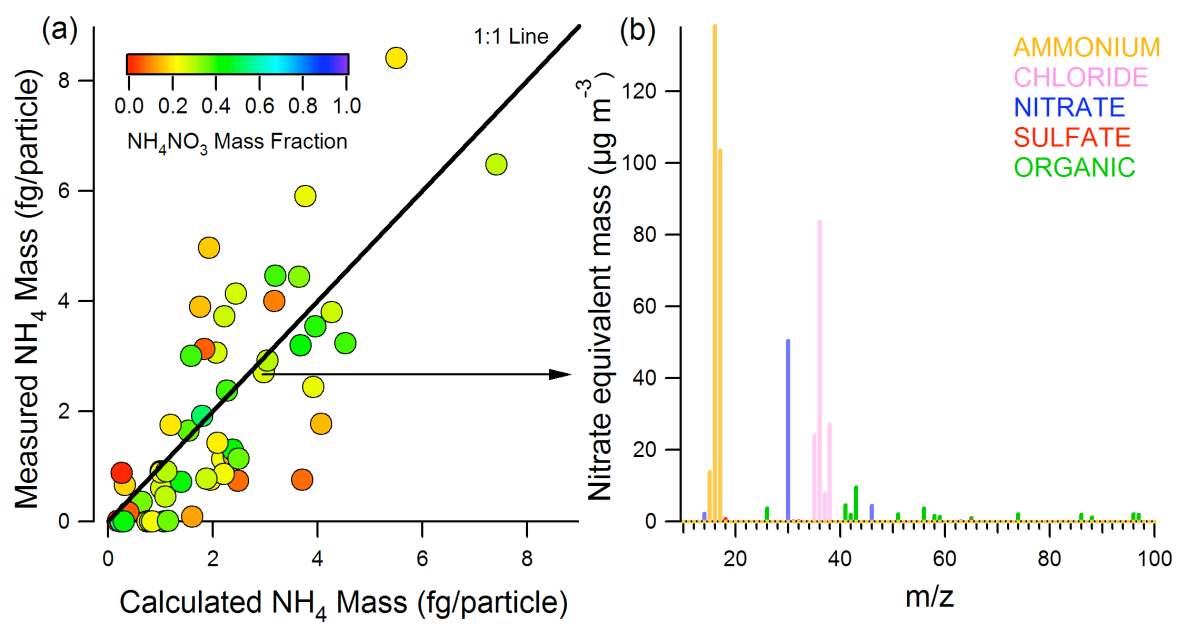

Fig. 13. (a) Measured (i.e. real) single particle $\mathrm{NH}_{4}$ mass plotted versus calculated single particle $\mathrm{NH}_{4}$ mass for the subset of single particles with high chloride content. (b) Single particle mass spectrum for a typical high chloride content particle (identified in (a) with the arrow).

in ensemble measured chloride shown in Fig. 8. The presence of this chemically distinct subset of high nonrefractory chloride-content particles indicates that a specific, identifiable source may be responsible for their emissions.

During MCMA-2003 Salcedo et al. (2006) reported the detection of large plumes of $\mathrm{NH}_{4} \mathrm{Cl}$ at the CENICA supersite. During the MILAGRO study, an ATOFMS located at the T0 site measured significant numbers of particles in the submicron and supermicron size ranges between 02:0005:00 LT each morning which were internally mixed $\mathrm{Pb}-\mathrm{Zn}$ $\mathrm{Cl}$ particles (Moffet et al., 2008a, b). Given this mixed composition, and the spatial and temporal distribution of $\mathrm{PbZnCl}$ particles, the early morning chloride particles were linked by these authors to emissions from industrial sites located in the northern region of the city. In addition to industrial sources, potential sources of chloride in the MCMA region include emissions from biomass burning (DeCarlo et al., 2008), trash burning, drinking water, and waste-water treatment facilities (Tanaka et al., 2003).

The single particle measurements made with the LS-ToFAMS are not chemically sensitive to heavy metal species such as $\mathrm{Zn}$ and $\mathrm{Pb}$ because the time scale for vaporization of such species is longer than the $5.4 \mathrm{~ms}$ PTOF saving interval. On the other hand, ensemble measurements in MS mode can be examined over longer time scales (minutes) and can help determine if heavy metals were present in the aerosol particles. Close examination of the ensemble data acquired during time periods of high chloride signal indicate that detectable $\mathrm{Pb}$ ions were measured in about half of the instances of high particulate chloride, suggesting potentially different sources for particulate chloride at $\mathrm{T} 1$. The correlation of lead and chloride in the ensemble data for some events may correlate with the $\mathrm{Pb}-\mathrm{Zn}-\mathrm{Cl}$ particle source observed by Moffet et al. (2008b).
The prompt single particle chloride measured with the LS-ToF-AMS was nonrefractory ammonium chloride, as indicated by the mass balance examination of the $\mathrm{NH}_{4}$ content of the high chloride content single particles displayed in Fig. 13a. These results are consistent with the simultaneous ensemble data measured by the LS-ToF-AMS and the results of Salcedo et al. (2006) during MCMA-2003. Figure 13a plots the measured prompt single particle $\mathrm{NH}_{4}$ mass (fg per particle) as a function of the amount of calculated $\mathrm{NH}_{4}$ required to fully neutralize the per particle inorganic content (i.e. neutralized to $\left(\mathrm{NH}_{4}\right)_{2} \mathrm{SO}_{4}, \mathrm{NH}_{4} \mathrm{NO}_{3}$, and $\mathrm{NH}_{4} \mathrm{Cl}$ ). The correlation is linear with a slope near the displayed 1:1 line $\left(R^{2}=0.75\right.$; slope $\left.=0.95\right)$. The particles displayed in Fig. 13a have $\mathrm{NH}_{4} \mathrm{Cl}$ mass fractions of 0.40 or greater (measured nonrefractory particle mass) and most were internally mixed with $\mathrm{NH}_{4} \mathrm{NO}_{3}$. The $\mathrm{NH}_{4} \mathrm{NO}_{3}$ mass fraction of each particle is indicated by the color of the data points as indicated in the legend. In Fig. 13b, we show the mass spectrum for the single particle denoted with an arrow in Fig. 13a. The mass spectrum shows that this particle was predominately $\mathrm{NH}_{4} \mathrm{Cl}$ combined with some $\mathrm{NH}_{4} \mathrm{NO}_{3}$ and very little organic.

To rule out the possibility that refractory chloride particles could evolve ammonium chloride in the LS-ToF-AMS PTOF time frame due to the heated vaporizer $\left(600^{\circ} \mathrm{C}\right)$ and high levels of gas phase ammonia, the size information obtained with the LS-ToF-AMS was analyzed for evidence of heavy metals in single particle densities (Cross et al., 2007). The densities of $\mathrm{PbCl}_{2}$ and $\mathrm{ZnCl}_{2}$ are $5.85 \mathrm{~g} / \mathrm{cm}^{3}$ and $2.90 \mathrm{~g} / \mathrm{cm}^{3}$, respectively. If a single particle were predominately composed of these species it would have a significantly higher density than the majority of other submicron ambient aerosol particles (typically $\rho=0.9-1.8 \mathrm{~g} / \mathrm{cm}^{3}$ ). The simultaneous measure of $d_{\mathrm{va}}$ and $d_{\mathrm{o}}$ provides a per particle measure of the effective density of all single particles, independent of chemical 
detection. Examination of all single particles measured during the high chloride particle events show that no particles had effective densities greater than $1.8 \mathrm{~g} / \mathrm{cm}^{3}$. This evidence suggests that if $\mathrm{PbCl}_{2}$ and $\mathrm{ZnCl}_{2}$ were present in the particles, they comprised a relatively minor amount of the prompt single particle chemical composition.

The temporal trend of these externally mixed ammonium chloride particles is consistent with the meteorological conditions at the T1 site. During the early morning, when the high chloride content particle types were observed, the temperature was low and the relative humidity was high, conditions that favor the formation and condensation of ammonium chloride from reaction of $\mathrm{HCl}_{(\mathrm{g})}$ and $\mathrm{NH}_{3(\mathrm{~g})}$ (San Martini et al., 2006a; San Martini et al., 2006b; Salcedo et al., 2006). However, unlike the single particle observations for ammonium nitrate (early morning photochemistry), sulfate ( $\mathrm{SO}_{2}$ plume), and OOA (afternoon photochemistry), the high chloride content particle types appear to be externally mixed within the prompt single particle sample (and thus the ambient aerosol). Thus, these high ammonium chloride content particles likely have a specific, though yet unidentified, source (e.g. emitted as primary particles in a plume) rather than the result of gas-to-particle condensation processes.

\section{Summary}

The first single particle results obtained with an Aerodyne time-of-flight aerosol mass spectrometer coupled with a light scattering module (LS-ToF-AMS) have been presented. Results from this preliminary study show that the LS-ToF-AMS acquired both ensemble average and single particle data. Particle counting statistics were limited for this initial version of the LS-ToF-AMS due to slow data transfer rates, high background signals, and a high particle size detection limit. Further development of the technique is underway to alleviate these limitations.

In total 12,853 single particles were optically triggered and saved during the 75-hour sampling period. Detection of correlated light scattering and chemical ion signals allowed for a detailed examination of the vaporization/ionization process for single particles measured with the AMS instrument. Three particle vaporization event types were identified: (1) prompt vaporization, (2) delayed vaporization, and (3) null. Unlike prompt and delayed vaporization events, null vaporization events did not produce a measurable chemical ion signal and were only detected optically. Prompt, delayed, and null particle vaporization events accounted for 23,26 , and $51 \%$ of the total number of sampled ambient particles with $d_{\mathrm{va}}>350 \mathrm{~nm}$, respectively. Prompt particle events represent particles that vaporize immediately upon impact with the vaporizer, whereas delayed and null vaporization events are due to particle bounce (i.e. incomplete vaporization) in the AMS vaporizer. While more work must be done to elucidate the details of the vaporization process, the single particle measurements shown here provide the first direct insight into the effect of particle bounce on particle detection in AMS. For example, these results suggest that the MS mode mass concentrations are higher than the PTOF mode concentrations because of delayed/null particle vaporization events which are more completely detected on the MS mode timescale which is three orders-of-magnitude longer than the PTOF mode. This analysis also indicates that delayed and null particle vaporization events are the likely cause for the non-unit AMS CE that was observed during this campaign.

Prompt single particle chemical ion signals exhibited a positive correlation with the total particle mass estimated from the calibrated scattered light intensity and the vacuum aerodynamic diameters. Analysis of the prompt single particles and the ensemble aerosol data was used to provide information about the mixing state and insights into the atmospheric transformations of the ambient aerosol ensemble. The prompt single particles were classified based on their measured nonrefractory mass fractions deconvolved from single particle mass spectra using techniques developed for ensemble AMS data analysis into hydrocarbonlike organic (HOA), oxygenated organic (OOA), $\mathrm{NH}_{4} \mathrm{NO}_{3}$, $\left(\mathrm{NH}_{4}\right)_{2} \mathrm{SO}_{4}$, and $\mathrm{NH}_{4} \mathrm{Cl}$. Most of the prompt single particles were internally mixed. The results show that the chemical compositions of the measured single particles changed diurnally as a result of secondary inorganic and organic formation/condensation processes. Specifically, the $\mathrm{NH}_{4} \mathrm{NO}_{3}$ content of all prompt single particles increased rapidly in the mid-morning due to photochemical production of $\mathrm{HNO}_{3}$ and peaked with an average of 0.6 ammonium nitrate mass fraction of the measured nonrefractory particulate mass. The ammonium nitrate (single particle mass fraction and ensemble mass loadings) decreased rapidly (likely due to evaporation) as the temperature and boundary layer increased in the late morning. Likewise, an increase in the OOA content of the single particles (and ensemble mass loadings) was observed from noon local time (increasing as the ammonium nitrate mass fraction was decreasing) and extending through the afternoon and evening and into early morning.

External mixing was observed for two different particle types. During the early morning and late evening rush hour periods, a subset of particles predominately composed of HOA (attributed to local combustion sources) were measured. Measurement of freshly emitted, primary HOA particles offers the opportunity to track subsequent atmospheric transformations of primary particles. The externally mixed HOA particle number fraction (of measured prompt single particles) went to zero during the late morning photochemical production and condensation of ammonium nitrate and stayed low until late evening through the early morning when the number fraction started to increase again. These observations are consistent with the primary HOA particles, likely emitted from a near-by highway, rapidly becoming internally mixed with secondary inorganic and organic compounds prior to sampling. In addition to primary HOA 
particles, a subset of prompt single particles with high nonrefractory chloride mass fractions was identified during the early morning. The chemically distinct nature of these particles suggests that they may have originated from a near-by source.

\section{Appendix A}

\section{Data acquisition}

Without the light scattering unit, the C-ToF-AMS can operate in three data acquisition modes: Mass Spectrum (MS) mode, Particle Time-of-Flight (PToF) mode, and "Brute Force" Single Particle (BFSP) mode. These modes of operation are described in detail by Drewnick et al. (2005) and DeCarlo et al. (2006). The addition of the light scattering module provides a fourth mode of operation designated as the Light Scattering-Single Particle mode (LSSP). The first two modes are ensemble aerosol measurements, whereas the latter two are single particle modes of operation. The first three modes of operation will be discussed here briefly, the fourth mode will be discussed in greater detail.

\section{A1 Mass Spectrum (MS) and Particle Time of Flight (PTOF) modes}

As described previously, the TOFMS in the ToF-AMS instruments is a pulsed, orthogonal extraction time-of-flight mass spectrometer. The pulsers were operated at $56 \mathrm{kHz}$ (every $18 \mu \mathrm{s}$ ) during the MILAGRO study. Thus, the measure of ion signals (i.e. molecules or mass) is determined as a flux of ions in time, similar to the quadrupole aerosol mass spectrometer, rather than the integral of ions from a single event, such as the ablation and ionization of a single particle in a laser-based aerosol mass spectrometer. In the MS mode, the chopper is alternately closed (blocking the particle beam) and opened (typically on a time scale of a few seconds) and full mass spectra are acquired and averaged for each time period. The difference in the ion signals acquired at each $\mathrm{m} / \mathrm{z}$ in the open and closed periods provides the difference mass spectrum for the particle ensemble.

In the PTOF mode, the chopper wheel rotates at a frequency of $130 \mathrm{~Hz}$. During each chopper cycle (i.e. slit to slit), particles enter the time-of-flight chamber through one of two slits in the chopper wheel. The two slits together comprised $1 \%$ of the total chopper area. Thus the sampling duty cycle in the PTOF mode is $10^{-2}$. A single PTOF data file consists of 300 mass spectra acquired during the $\sim 5.4 \mathrm{~ms}$ of sampling time during a given chopper cycle (each mass spectrum is acquired in $18 \mu \mathrm{s}$ ). Particle velocity is obtained from the measured time interval between the chopper slit opening $\left(t_{0}\right)$ and chemical ion signal $\left(t_{f}\right)$ provided by the vaporized and ionized particle. The vacuum aerodynamic diameter is calibrated using techniques described in Jayne et al. (2000).
In the PTOF mode, particles impact the vaporizer surface individually; however, signals are averaged over many chopper cycles so that average, size-resolved, chemically-speciated mass distributions are obtained.

\section{A2 Brute Force Single Particle (BFSP) mode}

The BFSP mode of ToF-AMS operation is similar to the PTOF mode, except that instead of averaging mass spectra from multiple chopper cycles, the series of 300 mass spectra for each chopper cycle are saved individually. Because the size of the data files saved during BFSP mode (dependent upon \# of chopper cycles saved) are significantly larger than the files saved in MS and PTOF modes, it is important to review the mechanism of filtering and saving particle information during single particle experiments.

Without a light scattering module, single particle data be can saved in one of two ways: 1) mass spectra are saved for all chopper cycles regardless of whether a particle entered the AMS during the chopper period or 2) mass spectra are saved only for single particles producing a pre-set sufficiently high chemical ion signal. The former method requires extensive post-processing of large data sets that are mainly zeros. Because the second method depends on setting a threshold for specific $\mathrm{m} / \mathrm{z}$ signals, chemical detection biases can be introduced if the composition of the particles is unknown.

The BFSP mode has been used for instrument calibrations and other laboratory experiments with well-defined particles such as ammonium nitrate particles. The practical application of the AMS as a true single particle instrument for measuring ambient particles required the development of a LSSP mode.

\section{A3 Light Scattering Single Particle (LSSP) mode}

The LSSP mode of ToF-AMS operation is similar to the BFSP mode, except that single particle light scattering signals trigger the saving of chemical ion data. For every particle optically detected within a chopper cycle, the series of 300 mass spectra $(300$ spectra $\times 18 \mu \mathrm{s}=5.4 \mathrm{~ms}$ PTOF time per chopper) and the light scattering signal for the complete chopper cycle are saved individually. Post-processing algorithms correlate each individual light scattering pulse with the integrated total chemical ion pulse (if any) that appears above the baseline (defined by the mass spectra that precede the particle arrival in PTOF time). As the single particle ion signals are typically small and exist on top of a constant background ion signal that is different for each $\mathrm{m} / \mathrm{z}, \mathrm{m} / \mathrm{z}$ specific thresholds are used to remove the DC off-set and reduce high frequency noise. Thresholds were set based on $3 \times$ the standard deviation of the background ion signal measured during the PTOF interval preceding the particle arrival at the vaporizer surface. Any ion signal that exceeds the $m / z$-specific threshold provides a measure of the single particle chemical signature and is integrated to provide a total 
chemical ion signal as a function of PTOF time (i.e. 300 mass spectra). The maximum signal of the total chemical ion pulse is used to determine the timing associated with the single particle vaporization event (e.g. prompt, delayed, or null). Finally, the $m / z$-specific chemical ion signals are integrated across a window $0.612 \mathrm{~ms}$ wide to produce a single particle mass spectrum.

The LSSP mode offers three distinct advantages over the BFSP mode in measuring the mass spectra of single particles. First, instead of saving mass spectra for every chopper cycle (as in the BFSP mode, option 1), the LSSP mode saves mass spectra only if a light scattering pulse is observed during that chopper cycle. Second, the optical diameter and the vacuum aerodynamic diameter of each particle are measured and from these two parameters, the effective density and total particle mass can be calculated for each particle, independent of the mass spectrometer measurements. Third, the arrival time of the particle at the vaporizer surface can be calculated from the measured particle time-of-flight between the chopper slit and scattered light pulse. This measurement provides information about the efficiency and time-scale of the vaporization/ionization process for each sampled particle.

The two disadvantages of the early version of the LSSP mode used during MILAGRO were (1) only particles larger then a optical detection limit of $d_{\mathrm{p}} \sim 250 \mathrm{~nm}$ were detected and (2) the actual duty cycle of the LSSP mode as deployed in Mexico was very low, only about $10^{-4}$ (see below). The optical detection limit, as deployed in Mexico City, was a single value that was conservatively chosen to ensure that all saved data represented real particles. The optical detection limit was not the ultimate limiting factor because the LS-ToF-AMS instrument deployed at T1 in Mexico City had a chamber background that limited single particle chemical detection (for an adequate number of $\mathrm{m} / \mathrm{z}$ signals) to approximately the same $d_{\mathrm{p}} \sim 250 \mathrm{~nm}$ optical diameter threshold (see Fig. 6 in Sect. 3.4).

The low duty cycle was due to the fact that the light scattering signal was collected in the second $2 \mathrm{GHz}$ DAQ channel to ensure direct correlation with the mass spectral signal for each particle. Thus, a significant fraction of the LSSP mode duty cycle was due to transferring and saving the data. This is evident from the following quantitative considerations. The time required to transfer and save the large amount of data obtained for a single particle in the LSSP mode during MILAGRO was about $800 \mathrm{~ms}$. One chopper cycle was $\sim 5.4 \mathrm{~ms}$. Therefore, the sampling duty cycle of the PTOF mode was reduced by about $10^{-2}$ yielding a LSSP duty cycle of about $10^{-4}$. As a consequence, the LSSP data obtained during the $75 \mathrm{~h}$ sampling period contains $10^{4}$ fewer particles than the MS mode data $\left(\sim 3000\right.$ particles compared to $3 \times 10^{7}$ particles). The efficiency of the LSSP mode of operation is being improved in the second generation of the LS-ToF-AMS.

\section{Appendix B}

\section{Uncertainty in single particle mass measurements}

Figure $4 \mathrm{a}$ and $\mathrm{b}$ exhibit significant scatter that is attributed to uncertainty in the measurements of chemical ion signal, $d_{\mathrm{va}}$ and $d_{\mathrm{o}}$. The standard deviations determined from the binned data in Fig. 4a are approximately $43 \%$. Uncertainty in the chemical ion measurement was determined by analyzing the single particle response of the instrument to known size ammonium nitrate and di-octyl sebacate (DOS) particles. In laboratory calibration experiments, the variance in single particle ion signal (sum of nitrate ions and organic ions for each particle) for the two different particle types was found to be $\pm 10 \%$. The ammonium nitrate and DOS particles represent a best-case scenario (tightly focused particle beam and prompt vaporization) for chemical detection within the AMS. The variability in ion signal measured for non-spherical, chemically complex ambient aerosol particles will likely be greater than $\pm 10 \%$. The signal-to-noise from the single particle chemical ion signals made during the MILAGRO study were further limited by rather high chamber background signals during the field deployment (single particle chemical ion signals are difference measurements).

The diameter-derived particle mass is influenced by uncertainties in the $d_{\mathrm{va}}$ and $d_{\mathrm{o}}$ measurements. Uncertainty in the $d_{\mathrm{va}}$ is due to the timing uncertainty from the $1 \%$ chopper. With a $1 \%$ chopper slit and a chopper frequency of $130 \mathrm{~Hz}$, the timing uncertainty is $\sim 70 \mu$ s which corresponds to a maximum uncertainty in $d_{\mathrm{va}}$ of $13 \%$. Uncertainty in the $d_{\mathrm{o}}$ determination is caused by two factors. First, the spread in the light scattering signals caused by some particles passing through the center and others through the edges of the laser beam (laboratory studies have shown that spherical particles exhibit $11 \%$ uncertainty in scattered light signal; nonspherical particles will exhibit a higher uncertainty). Second, the calibration curve used to convert scattered light into an optical diameter is based on $\mathrm{NH}_{4} \mathrm{NO}_{3}$ particles. For particles with a refractive index that is different from the refractive index of $\mathrm{NH}_{4} \mathrm{NO}_{3}$, an uncertainty in $d_{\mathrm{o}}$ is introduced. In the absence of black carbon, most nonrefractory sub-micron aerosol particles have a real refractive index between 1.4-1.6 (Seinfeld and Pandis, 2006). Across this range, the uncertainty in $d_{\mathrm{o}}$ is $\sim 10 \%$ (Cross et al., 2007). The majority of particles with prompt vaporization within the LS-ToF-AMS most likely fall within this refractive index range. The uncertainties in $d_{\mathrm{o}}$ due to refractive index and particle position in the laser each get doubled in the conversion to particle mass, causing the overall uncertainty in optical diameter derived mass to be $\sim 40 \%$. This uncertainty is an underestimate due to the known presence of black carbon particles, which absorb light at $\lambda=405 \mathrm{~nm}$ (the $\lambda$ of the detection laser in the LS-ToF-AMS). The uncertainty in the diameter-derived mass likely accounts for much of the variance in Fig. $4 a$ and $b$. Variations in the diameter-derived single particle mass will 
not affect the measurement of single particle chemical composition.

Acknowledgements. The authors gratefully acknowledge A. Laskin and Y. Dessiaterik for use of their SMPS system during instrument calibrations, B. de Foy and J. D. Fast for helpful discussions about the MCMA meteorology, R. C. Cohen for $\mathrm{HNO}_{3}$ and $\mathrm{NO}_{2}$ measurements at $\mathrm{T} 1$, and $\mathrm{G}$. Huey for $\mathrm{SO}_{2}$ measurements at $\mathrm{T} 1$. This research was supported by the Office of Science (BER), Department of Energy (Atmospheric Science Program) grants No. DE-FG02-05ER63995, DE-FG02-05ER84268, DOE DEFG02-05ER63982 and the Atmospheric Chemistry Program of the National Science Foundation grant No. ATM-0525355. ESC was funded by the NASA Earth System Science Fellowship program.

Edited by: L. Molina

\section{References}

Adachi, K. and Buseck, P. R.: Internally mixed soot, sulfates, and organic matter in aerosol particles from Mexico City, Atmos. Chem. Phys., 8, 6469-6481, 2008,

http://www.atmos-chem-phys.net/8/6469/2008/.

Aiken, A. C., Salcedo, D., Cubison, M. J., Huffman, J. A., DeCarlo, P. F., Ulbrich, I. M., Docherty, K. S., Sueper, D., Kimmel, J. R., Worsnop, D. R., Trimborn, A., Northway, M., Stone, E. A., Schauer, J. J., Volkamer, R. M., Fortner, E., de Foy, B., Wang, J., Laskin, A., Shutthanandan, V., Zheng, J., Zhang, R., Gaffney, J., Marley, N. A., Paredes-Miranda, G., Arnott, W. P., Molina, L. T., Sosa, G., and Jimenez, J. L.: Mexico City aerosol analysis during MILAGRO using high resolution aerosol mass spectrometry at the urban supersite (T0) - Part 1: Fine particle composition and organic source apportionment, Atmos. Chem. Phys., 9, 66336653, 2009,

http://www.atmos-chem-phys.net/9/6633/2009/.

Alfarra, M. R.: Insights into atmospheric organic aerosols using an Aerosol Mass Spectrometer, Ph.D Thesis, University of Manchester, Manchester, England, 2004.

Alfarra, M. R., Coe, H., Allan, J. D., Bower, K. N., Boudries, H., Canagaratna, M. R., Jimenez, J. L., Jayne, J. T., Garforth, A., Li, S. M., and Worsnop, D. R.: Characterization of Urban and Regional Organic Aerosols In the Lower Fraser Valley Using Two Aerodyne Aerosol Mass Spectrometers, Atmos. Environ., 38, 5745-5758, 2004.

Alfarra, M. R., Prevot, A. S. H., Szidat, S., Sandradewi, J., Weimer, S., Lanz, V. A., Schreiber, D., Mohr, M., and Baltensperger, U.: Identification of the mass spectral signature of organic aerosols from wood burning emissions, Environ. Sci. Technol., 41, 57705777, doi:10.1021/es062289b, 2007.

Allan, J. D., Jimenez, J. L., Coe, H., Bower, K. N., Williams, P. I., and Worsnop, D. R.: Quantitative sampling using an Aerodyne Aerosol Mass Spectrometer, Part 1: Techniques of data interpretation and error analysis, J. Geophys. Res.-Atmos., 108, 4090, 2003.

Bond, T. C. and Bergstrom, R. W.: Light absorption by carbonaceous particles: An investigative review, Aerosol Sci. Tech., 40, 27-67, doi:10.1080/02786820500421521, 2006.
Bravo, A. H., Sosa, E. R., Sanchez, A. P., Jaimes, P. M., and Saavedra, R. M. I.: Impact of wildfires on the air quality of Mexico City, 1992-1999, Environ. Pollut., 117, 243-253, 2002.

Canagaratna, M. R., Jayne, J. T., Ghertner, D. A., Herndon, S., Shi, Q., Jimenez, J. L., Silva, P. J., Williams, P., Lanni, T., Drewnick, F., Demerjian, K. L., Kolb, C. E., and Worsnop, D. R.: Chase studies of particulate emissions from in-use New York City vehicles, Aerosol Sci. Tech., 38, 555-573, 2004.

Canagaratna, M. R., Jayne, J. T., Jimenez, J. L., Allan, J. D., Alfarra, M. R., Zhang, Q., Onasch, T. B., Drewnick, F., Coe, H., Middlebrook, A., Delia, A., Williams, L. R., Trimborn, A. M., Northway, M. J., Kolb, C. E., Davidovits, P., and Worsnop, D. R.: Chemical and microphysical characterization of ambient aerosols with the Aerodyne Aerosol Mass Spectrometer, Mass Spectrom. Rev., 26, 185-222, 2007.

Chylek, P., Videen, G., Ngo, D., Pinnick, R. G., and Klett, J. D.: Effect of black carbon on the optical-properties and climate forcing of sulfate aerosols, J. Geophys. Res.-Atmos., 100, 16325-16332, 1995.

Chow, J. C., Watson, J. G., Edgerton, S. A., and Vega, E.: Chemical composition of $\mathrm{PM}_{2.5}$ and $\mathrm{PM}_{10}$ in Mexico City during winter 1997, Sci. Total Environ., 287, 177-201, 2002.

Cross, E. S., Slowik, J. G., Davidovits, P., Allan, J. D., Worsnop, D. R., Jayne, J. T., Lewis, D. K., Canagaratna, M., and Onasch, T. B.: Laboratory and ambient particle density determinations using light scattering in conjunction with aerosol mass spectrometry, Aerosol Sci. Tech., 41, 343-359, doi:10.1080/02786820701199736, 2007.

de Foy, B., Fast, J. D., Paech, S. J., Phillips, D., Walters, J. T., Coulter, R. L., Martin, T. J., Pekour, M. S., Shaw, W. J., Kastendeuch, P. P., Marley, N. A., Retama, A., and Molina, L. T.: Basinscale wind transport during the MILAGRO field campaign and comparison to climatology using cluster analysis, Atmos. Chem. Phys., 8, 1209-1224, 2008,

http://www.atmos-chem-phys.net/8/1209/2008/.

de Gouw, J. A., Middlebrook, A. M., Warneke, C., Goldan, P. D., Kuster, W. C., Roberts, J. M., Fehsenfeld, F. C., Worsnop, D. R., Canagaratna, M. R., Pszenny, A. A. P., Keene, W. C., Marchewka, M., Bertman, S. B., and Bates, T. S.: The Budget of Organic Carbon in a Polluted Atmosphere: Results from the New England Air Quality Study in 2002, J. Geophys. Res.-Atmos., 110, D16305, doi:10.1029/2004JD005623, 2005.

DeCarlo, P., Slowik, J. G., Worsnop, D. R., Davidovits, P., and Jimenez, J. L.: Particle Morphology and Density Characterization by Combined Mobility and Aerodynamic Diameter Measurements, Part 1: Theory, Aerosol Sci. Tech., 38, 1185-1205, 2004.

DeCarlo, P. F., Kimmel, J., Trimborn, A., Northway, M., Jayne, J. T., Aiken, A., Gonin, M., Fuhrer, K., Horvath, T., Docherty, K., Worsnop, D. R., and Jimenez, J. L.: Field-deployable, high-resolution, time-of-flight Aerosol Mass Spectrometer, Anal. Chem., 78, 8281-8289, 2006.

DeCarlo, P. F., Dunlea, E. J., Kimmel, J. R., Aiken, A. C., Sueper, D., Crounse, J., Wennberg, P. O., Emmons, L., Shinozuka, Y., Clarke, A., Zhou, J., Tomlinson, J., Collins, D. R., Knapp, D., Weinheimer, A. J., Montzka, D. D., Campos, T., and Jimenez, J. L.: Fast airborne aerosol size and chemistry measurements above Mexico City and Central Mexico during the MILAGRO campaign, Atmos. Chem. Phys., 8, 4027-4048, 2008, 
http://www.atmos-chem-phys.net/8/4027/2008/.

Docherty, K. S., Stone, E. A., Ulbrich, I. M., DeCarlo, P. F., Snyder, D. C., Schauer, J. J., Peltier, R. E., Weber, R. J., Murphy, S. M., Seinfeld, J. H., Grover, B. D., Eatough, D. J., and Jimenez, J. L.: Apportionment of Primary and Secondary Organic Aerosols in Southern California during the 2005 Study of Organic Aerosols in Riverside (SOAR), Environ. Sci. Technol., 42, 7655-7662, doi:10.1021/es8008166, 2008.

Doran, J. C., Barnard, J. C., Arnott, W. P., Cary, R., Coulter, R., Fast, J. D., Kassianov, E. I., Kleinman, L., Laulainen, N. S., Martin, T., Paredes-Miranda, G., Pekour, M. S., Shaw, W. J., Smith, D. F., Springston, S. R., and Yu, X.-Y.: The T1-T2 study: evolution of aerosol properties downwind of Mexico City, Atmos. Chem. Phys., 7, 1585-1598, 2007,

http://www.atmos-chem-phys.net/7/1585/2007/.

Drewnick, F., Schwab, J. J., Hogrefe, O., Peters, S., Husain, L., Diamond, D., Weber, R., and Demerjian, K. L.: Intercomparison and Evaluation of Four Semi-continuous $\mathrm{PM}_{2.5}$ Sulfate Instruments, Atmos. Environ., 37, 3335-3350, 2003.

Drewnick, F., Hings, S. S., DeCarlo, P., Jayne, J. T., Gonin, M., Fuhrer, K., Weimer, S., Jimenez, J. L., Demerjian, K. L., Borrmann, S., and Worsnop, D. R.: A new time-of-flight Aerosol Mass Spectrometer (ToF-AMS) - instrument description and first field deployment, Aerosol Sci. Tech., 39, 637-658, 2005.

Fast, J. D., de Foy, B., Acevedo Rosas, F., Caetano, E., Carmichael, G., Emmons, L., McKenna, D., Mena, M., Skamarock, W., Tie, X., Coulter, R. L., Barnard, J. C., Wiedinmyer, C., and Madronich, S.: A meteorological overview of the MILAGRO field campaigns, Atmos. Chem. Phys., 7, 2233-2257, 2007, http://www.atmos-chem-phys.net/7/2233/2007/.

Fast, J., Aiken, A. C., Allan, J., Alexander, L., Campos, T., Canagaratna, M. R., Chapman, E., DeCarlo, P. F., de Foy, B., Gaffney, J., de Gouw, J., Doran, J. C., Emmons, L., Hodzic, A., Herndon, S. C., Huey, G., Jayne, J. T., Jimenez, J. L., Kleinman, L., Kuster, W., Marley, N., Russell, L., Ochoa, C., Onasch, T. B., Pekour, M., Song, C., Ulbrich, I. M., Warneke, C., WelshBon, D., Wiedinmyer, C., Worsnop, D. R., Yu, X.-Y., and Zaveri, R.: Evaluating simulated primary anthropogenic and biomass burning organic aerosols during MILAGRO: implications for assessing treatments of secondary organic aerosols, Atmos. Chem. Phys., 9, 6191-6215, 2009, http://www.atmos-chem-phys.net/9/6191/2009/.

Hennigan, C. J., Sullivan, A. P., Fountoukis, C. I., Nenes, A., Hecobian, A., Vargas, O., Peltier, R. E., Case Hanks, A. T., Huey, L. G., Lefer, B. L., Russell, A. G., and Weber, R. J.: On the volatility and production mechanisms of newly formed nitrate and water soluble organic aerosol in Mexico City, Atmos. Chem. Phys., 8, 3761-3768, 2008,

http://www.atmos-chem-phys.net/8/3761/2008/.

Herndon, S. C., Onasch, T. B., Wood, E. C., Kroll, J. H., Canagaratna, M. R., Jayne, J. T., Zavala, M. A., Knighton, W. B., Mazzoleni, C., Dubey, M. K., Ulbrich, I. M., Jimenez, J. L., Seila, R., de Gouw, J. A., de Foy, B., Fast, J., Molina, L. T., Kolb, C. E., and Worsnop, D. R.: The correlation of secondary organic aerosol with odd oxygen in Mexico City, Geophys. Res. Lett., 35, L15804, doi:10.1029/2008GL034058, 2008.

Hogrefe, O. S. J., Drewnick, F., Lala, G. G., Peters, S., Demerjian, K. L., Rhoads, K., Felton, H. D., Rattigan, O. V., Husain, L., and Dutkiewicz, V. A.: Semicontinuous $\mathrm{PM}_{2.5}$ sulfate and ni- trate measurements at an urban and a rural location in New York: PMTACS-NY summer 2001 and 2002 campaigns, J. Air Waste Manage., 54, 1040-1060, 2004.

Jayne, J. T., Leard, D. C., Zhang, X., Davidovits, P., Smith, K. A., Kolb, C. E., and Worsnop, D. R.: Development of an Aerosol Mass Spectrometer for size and composition analysis of submicron particles, Aerosol Sci. Technol., 33, 49-70, 2000.

Jimenez, J. L., Jayne, J. T., Shi, Q., Kolb, C. E., Worsnop, D. R., Yourshaw, I., Seinfeld, J. H., Flagan, R. C., Zhang, X., Smith, K. A., Morris, J. W., and Davidovits, P.: Ambient aerosol sampling using the Aerodyne Aerosol Mass Spectrometer, J. Geophys. Res., 108, 8425, doi:8410.1029/2001JD001213, 2003.

Johnson, K. S., Zuberi, B., Molina, L. T., Molina, M. J., Iedema, M. J., Cowin, J. P., Gaspar, D. J., Wang, C., and Laskin, A.: Processing of soot in an urban environment: case study from the Mexico City Metropolitan Area, Atmos. Chem. Phys., 5, 3033 3043, 2005,

http://www.atmos-chem-phys.net/5/3033/2005/.

Johnson, K. S., de Foy, B., Zuberi, B., Molina, L. T., Molina, M. J., Xie, Y., Laskin, A., and Shutthanandan, V.: Aerosol composition and source apportionment in the Mexico City Metropolitan Area with PIXE/PESA/STIM and multivariate analysis, Atmos. Chem. Phys., 6, 4591-4600, 2006,

http://www.atmos-chem-phys.net/6/4591/2006/.

Johnson, K. S., Laskin, A., Jimenez, J. L., Shutthanandan, V., Molina, L. T., Salcedo, D., Dzepina, K., and Molina, M. J.: Comparative analysis of urban atmospheric aerosol by ProtonInduced X-ray Emission (PIXE), Proton Elastic Scattering Analysis (PESA), and Aerosol Mass Spectrometry (AMS), Environ. Sci. Technol., 42, 6619-6624, 2008.

Kleinman, L. I., Springston, S. R., Daum, P. H., Lee, Y.-N., Nunnermacker, L. J., Senum, G. I., Wang, J., Weinstein-Lloyd, J., Alexander, M. L., Hubbe, J., Ortega, J., Canagaratna, M. R., and Jayne, J.: The time evolution of aerosol composition over the Mexico City plateau, Atmos. Chem. Phys., 8, 1559-1575, 2008, http://www.atmos-chem-phys.net/8/1559/2008/.

Kondo, Y., Miyazaki, Y., Takegawa, N., Miyakawa, T., Weber, R. J., Jimenez, J. L., Zhang, Q., and Worsnop, D. R.: Oxygenated and Water-soluble Organic Aerosols in Tokyo, J. Geophys. Res.Atmos., 112(D1), D01203, doi:10.1029/2006JD007056, 2007.

Lanz, V. A., Alfarra, M. R., Baltensperger, U., Buchmann, B., Hueglin, C., and Prévôt, A. S. H.: Source apportionment of submicron organic aerosols at an urban site by factor analytical modelling of aerosol mass spectra, Atmos. Chem. Phys., 7, 15031522, 2007, http://www.atmos-chem-phys.net/7/1503/2007/.

Lanz, V. A., Alfarra, M. R., Baltensperger, U., Buchmann, B., Hueglin, C., Szidat, S., Wehrli, M. R., Wacker, L., Weimer, S., Caseiro, A., Puxbaum, H., and Prevot, A. S. H.: Source attribution of submicron organic aerosols during wintertime inversions by advanced factor analysis of aerosol mass spectra, Environ. Sci. Technol., 42, 214-220, 2007 b.

Lesins, G., Chylek, P., and Lohmann, U.: A study of internal and external mixing scenarios and its effect on aerosol optical properties and direct radiative forcing, J. Geophys. Res., 110, D07S09, doi:10.1029/2001JD000973, 2002.

Liu, P. S. K., Deng, R., Smith, K. A., Williams, L. R., Jayne, J. T., Canagaratna, M. R., Moore, K., Onasch, T. B., Worsnop, D. R. and Deshler, T.: Transmission efficiency of an aerodynamic fo- 
cusing lens system: Comparison of model calculations and laboratory measurements for the Aerodyne Aerosol Mass Spectrometer, Aerosol Sci. Tech., 41, 721-733, 2007.

Matthew, B. M., Onasch, T. B., and Middlebrook, A. M.: Collection efficiencies in an Aerodyne Aerosol Mass Spectrometer as a function of particle phase for laboratory generated aerosols, Aerosol Sci. Tech., 42, 884-898, 2008.

McMurry, P. H.: A review of atmospheric aerosol measurements, Atmos. Environ., 34, 1959-1999, 2000.

Moffet, R. C., de Foy, B., Molina, L. T., Molina, M. J., and Prather, K. A.: Measurement of ambient aerosols in northern Mexico City by single particle mass spectrometry, Atmos. Chem. Phys., 8, 4499-4516, 2008,

http://www.atmos-chem-phys.net/8/4499/2008/.

Moffet, R. C., Desyaterik, Y., Hopkins, R. J., Tivanski, A. V., Gilles, M. K., Wang, Y., Shutthanandan, V., Molina, L. T., Abraham, R. G., Johnson, K. S., Mugica, V., Molina, M. J., Laskin, A., and Prather, K. A.: Characterization of aerosols containing $\mathrm{Zn}, \mathrm{Pb}$, and $\mathrm{Cl}$ from an industrial region of Mexico City, Environ. Sci. Technol., 42, 7091-7097, 2008b.

Molina, L. T., Kolb, C. E., de Foy, B., Lamb, B. K., Brune, W. H., Jimenez, J. L., Ramos-Villegas, R., Sarmiento, J., ParamoFigueroa, V. H., Cardenas, B., Gutierrez-Avedoy, V., and Molina, M. J.: Air quality in North America's most populous city overview of the MCMA-2003 campaign, Atmos. Chem. Phys., 7, 2447-2473, 2007, http://www.atmos-chem-phys.net/7/2447/2007/.

Molina, L. T., Madronich, S., Gaffney J., et al.: An overview of the MILAGRO 2006 Campaign: Mexico City emissions and its transport and transformation, Atmos. Chem. Phys. Discuss., in preparation, 2009.

Moya, M., Castro, T., Zepeda, M., and Baez, A.: Characterization of size-differentiated inorganic composition of aerosols in Mexico City, Atmos. Environ., 37, 3581-3591, doi:10.1016/s13522310(03)00345-5, 2003.

Murphy, D. M.: The design of single particle laser mass spectrometers, Mass Spectrom. Rev., 26, 150-165, 2007.

Nash, D. G., Baer, T., and Johnston, M. V.: Aerosol mass spectrometry: An introductory review, Int. J. Mass Spectrom., 258, 2-12, 2006.

Paredes-Miranda, G., Arnott, W. P., Jimenez, J. L., Aiken, A. C., Gaffney, J. S., and Marley, N. A.: Primary and secondary contributions to aerosol light scattering and absorption in Mexico City during the MILAGRO 2006 campaign, Atmos. Chem. Phys., 9, 3721-3730, 2009, http://www.atmos-chem-phys.net/9/3721/2009/.

Petters, M. D., Prenni, A. J., Kreidenweis, S. M., DeMott, P. J., Matsunaga, A., Lim, Y. B., and Ziemann, P. J.: Chemical aging and the hydrophobic-to-hydrophilic conversion of carbonaceous aerosol, Geophys. Res. Lett., 33, L24806, doi:10.1029/2006GL027249, 2006.

Querol, X., Pey, J., Minguillón, M. C., Pérez, N., Alastuey, A., Viana, M., Moreno, T., Bernabé, R. M., Blanco, S., Cárdenas, B., Vega, E., Sosa, G., Escalona, S., Ruiz, H., and Artíñano, B.: PM speciation and sources in Mexico during the MILAGRO-2006 Campaign, Atmos. Chem. Phys., 8, 111-128, 2008, http://www.atmos-chem-phys.net/8/111/2008/.

Quinn, P. K., Bates, T. S., Coffman, D., Onasch, T. B., Worsnop, D., Baynard, T., de Gouw, J. A., Goldan, P. D., Kuster, W.
C., Williams, E., Roberts, J. M., Lerner, B., Stohl, A., Pettersson, A., and Lovejoy, E. R.: Impacts of Sources and Aging on Submicrometer Aerosol Properties in the Marine Boundary Layer Across the Gulf of Maine, J. Geophys. Res., 111, D23S36, doi:10.1029/2006JD007582, 2006

Sakurai, H., Tobias, H. J., Park, K., Zarling, D., Docherty, S., Kittelson, D. B., McMurry, P. H., and Ziemann, P. J.: On-line measurements of diesel nanoparticle composition and volatility, Atmos. Environ., 37, 1199-1210, doi:10.1016/s1352-2310(02)01017-8, 2003.

Salcedo, D., Onasch, T. B., Dzepina, K., Canagaratna, M. R., Zhang, Q., Huffman, J. A., DeCarlo, P. F., Jayne, J. T., Mortimer, P., Worsnop, D. R., Kolb, C. E., Johnson, K. S., Zuberi, B., Marr, L. C., Volkamer, R., Molina, L. T., Molina, M. J., Cardenas, B., Bernabé, R. M., Márquez, C., Gaffney, J. S., Marley, N. A., Laskin, A., Shutthanandan, V., Xie, Y., Brune, W., Lesher, R., Shirley, T., and Jimenez, J. L.: Characterization of ambient aerosols in Mexico City during the MCMA-2003 campaign with Aerosol Mass Spectrometry: results from the CENICA Supersite, Atmos. Chem. Phys., 6, 925-946, 2006, http://www.atmos-chem-phys.net/6/925/2006/.

San Martini, F. M., Dunlea, E. J., Grutter, M., Onasch, T. B., Jayne, J. T., Canagaratna, M. R., Worsnop, D. R., Kolb, C. E., Shorter, J. H., Herndon, S. C., Zahniser, M. S., Ortega, J. M., McRae, G. J., Molina, L. T., and Molina, M. J.: Implementation of a Markov Chain Monte Carlo method to inorganic aerosol modeling of observations from the MCMA-2003 campaign - Part I: Model description and application to the La Merced site, Atmos. Chem. Phys., 6, 4867-4888, 2006,

http://www.atmos-chem-phys.net/6/4867/2006/.

San Martini, F. M., Dunlea, E. J., Volkamer, R., Onasch, T. B., Jayne, J. T., Canagaratna, M. R., Worsnop, D. R., Kolb, C. E., Shorter, J. H., Herndon, S. C., Zahniser, M. S., Salcedo, D., Dzepina, K., Jimenez, J. L., Ortega, J. M., Johnson, K. S., McRae, G. J., Molina, L. T., and Molina, M. J.: Implementation of a Markov Chain Monte Carlo method to inorganic aerosol modeling of observations from the MCMA-2003 campaign Part II: Model application to the CENICA, Pedregal and Santa Ana sites, Atmos. Chem. Phys., 6, 4889-4904, 2006, http://www.atmos-chem-phys.net/6/4889/2006/.

Schneider, J., Weimer, S., Drewnick, F., Borrmann, S., Helas, G., Gwaze, P., Schmid, O., Andreae, M. O., and Kirchner, U.: Mass spectrometric analysis and aerodynamic properties of various types of combustion-related aerosol particles, Int. J. Mass Spectrom., 258, 37-49, doi:10.1016/j.ijms.2006.07.008, 2006.

Seinfeld, J. H. and Pandis, S. N.: Atmospheric chemistry and physics: From air pollution to climate change, John Wiley \& Sons, Inc., New York, 2006.

Shilling, J. E., King, S. M., Mochida, M., and Martin, S. T.: Mass spectral evidence that small changes in composition caused by oxidative aging processes alter aerosol CCN properties, J. Phys. Chem., 25, 3358-3368, 2007.

Simoneit, B. R. T.: Biomass burning - a review of organic tracers for smoke from incomplete combustion, Appl. Geochem., 17, 129-162, 2002.

Sinha, M. P. and Friedlander, S. K.: Real-time measurement of sodium chloride in individual aerosol particles by mass spectrometry, Anal. Chem., 57(9), 1880-1883, doi: $10.1021 / \mathrm{ac} 00286 \mathrm{a} 019,1985$. 
Slowik, J. G., Stainken, K., Davidovits, P., Williams, L. R., Jayne, J. T., Kolb, C. E., Worsnop, D. R., Rudich, Y., DeCarlo, P., and Jimenez, J. L.: Particle Morphology and Density Characterization by Combined Mobility and Aerodynamic Diameter Measurements, Part 2: Application to Combustion Generated Soot Particles as a Function of Fuel Equivalence Ratio, Aerosol Sci. Technol., 38, 1206-1222, 2004.

Solomon, S., Qin, D., Manning, M., Marquis, M., Averyt, K., Tignor, M., and Miller, H. L. E.: IPCC: Climate change 2007: The scientific basis, contribution of working group I to the fourth assessment report of the Intergovernmental Panel on Climate Change, Cambridge University Press, Cambridge, UK and New York, NY, USA, 2007.

Stone, E. A., Snyder, D. C., Sheesley, R. J., Sullivan, A. P., Weber, R. J., and Schauer, J. J.: Source apportionment of fine organic aerosol in Mexico City during the MILAGRO experiment 2006, Atmos. Chem. Phys., 8, 1249-1259, 2008, http://www.atmos-chem-phys.net/8/1249/2008/.

Sullivan, R. C. and Prather, K. A.: Recent advances in our understanding of atmospheric chemistry and climate made possible by on-line aerosol analysis instrumentation, Anal. Chem., 77, 38613886, 2005.

Takegawa, N. M. Y., Kondo, Y., Komazaki, Y., Miyakawa, T., Jimenez, J. L., Jayne, J. T., Allan, J. D., and Weber, R. J.: Characterization of an Aerodyne Aerosol Mass Spectrometer (AMS): Intercomparison with other aerosol instruments, Aerosol Sci. Tech., 39, 760-770, 2005.

Takegawa, N., Miyakawa, T., Kondo, Y., Jimenez, J. L., Zhang, Q., Worsnop, D. R., and Fukuda, M.: Seasonal and Diurnal Variations of Submicron Organic Aerosols in Tokyo Observed using the Aerodyne Aerosol Mass Spectrometer (AMS), J. Geophys. Res.-Atmos., 111, D11206, doi:10.1029/2005JD006515, 2006.

Tanaka, P. L., Riemer, D. D., Chang, S., Yarwood, G., McDonald Buller, E. C., Apel, E. C., Orlando, J. J., Silva, P. J., Jimenez, J. L., Canagaratna, M. R., Neece, J. D., Mullins, C. B., and Allen, D. T.: Direct evidence for chlorine-enhanced urban ozone formation in Houston, Texas, Atmos. Environ., 37, 1393-1400, 2003.
Ulbrich, I. M., Canagaratna, M. R., Zhang, Q., Worsnop, D. R., and Jimenez, J. L.: Interpretation of organic components from Positive Matrix Factorization of aerosol mass spectrometric data, Atmos. Chem. Phys., 9, 2891-2918, 2009, http://www.atmos-chem-phys.net/9/2891/2009/.

Volkamer, R., Jimenez, J. L., San Martini, F., Dzepina, K., Zhang, Q., Salcedo, D., Molina, L. T., Worsnop, D. R., and Molina, M. J.: Secondary organic aerosol formation from anthropogenic air pollution: Rapid and higher than expected, Geophys. Res. Lett., 33, L17811, doi: 10.1029/2006gl026899, 2006.

Yokelson, R. J., Urbanski, S. P., Atlas, E. L., Toohey, D. W., Alvarado, E. C., Crounse, J. D., Wennberg, P. O., Fisher, M. E., Wold, C. E., Campos, T. L., Adachi, K., Buseck, P. R., and Hao, W. M.: Emissions from forest fires near Mexico City, Atmos. Chem. Phys., 7, 5569-5584, 2007, http://www.atmos-chem-phys.net/7/5569/2007/.

Zhang, Q., Canagaratna, M. R., Jayne, J. T., Worsnop, D. R., and Jimenez, J.-L.: Time- and size-resolved chemical composition of submicron particles in Pittsburgh: Implications for aerosol sources and processes, J. Geophys. Res., 110, D07S09, doi:10.1029/2004JD004649, 2005a.

Zhang, Q., Alfarra, M. R., Worsnop, D. R., Allan, J. D., Coe, H., Canagaratna, M. R., and Jimenez, J. L.: Deconvolution and quantification of hydrocarbon-like and oxygenated organic aerosols based on aerosol mass spectrometry, Environ. Sci. Technol., 39, 4938-4952, 2005b.

Zhang, Q., Worsnop, D. R., Canagaratna, M. R., and Jimenez, J. L.: Hydrocarbon-like and oxygenated organic aerosols in Pittsburgh: insights into sources and processes of organic aerosols, Atmos. Chem. Phys., 5, 3289-3311, 2005, http://www.atmos-chem-phys.net/5/3289/2005/.

Zheng, J., Zhang, R., Fortner, E. C., Volkamer, R. M., Molina, L., Aiken, A. C., Jimenez, J. L., Gaeggeler, K., Dommen, J., Dusanter, S., Stevens, P. S., and Tie, X.: Measurements of $\mathrm{HNO}_{3}$ and $\mathrm{N}_{2} \mathrm{O}_{5}$ using ion drift-chemical ionization mass spectrometry during the MILAGRO/MCMA-2006 campaign, Atmos. Chem. Phys., 8, 6823-6838, 2008, http://www.atmos-chem-phys.net/8/6823/2008/. 